\title{
Stochastic Petri-net models to predict the degradation of ceramic clad- dings
}

Abstract:

In this study, a stochastic Petri net formalism is proposed to predict the degradation of ceramic claddings over time to understand how different environmental exposure conditions contribute to the overall degradation of these claddings. For that purpose, the degradation condition of 195 ceramic claddings located in Lisbon (Portugal) is evaluated through in situ visual inspections. In the first part of the study, a stochastic deterioration Petri net model is proposed to the entire sample. In the second part, the original sample is divided according to the environmental exposure conditions, evaluating the influence of these conditions on the deterioration process of ceramic claddings. Four main degradation agents are analysed: exposure to moisture; distance from the sea; orientation; and the wind-rain action. The results obtained reveal that Petri nets can accurately describe the deterioration process of ceramic claddings, providing relevant information regarding the performance of these claddings through their life-cycle and according to the environmental exposure conditions to which they are subject to. These results are extremely relevant for different practitioners, allowing adopting more sustainable and durable solutions in a design stage, as well as improving the durability of the ceramic claddings by carrying optimised maintenance plans and strategies.

Keywords: deterioration; building envelope; building performance; facades; stochastic Petri net; environmental exposure conditions.

\section{$1 \quad$ Introduction}

The aging of the Europe building stock and the high burden related with their maintenance and repair, has increased the relevance of adopting condition-based maintenance plans and strategies (Hovde, 2002; Beer et al., 2011; Paulo et al., 2014; Silva et al., 2016). The decision-making concerning the maintenance and rehabilitation of the built heritage requires more economic and sustainability awareness, adopting technical criteria in the decision to intervene. However, this rational approach is only possible if reliable 
understanding of the durability and service life of building materials and components exists (Aikivuori, 1999).Therefore, in the last decades, various authors (Shohet et al., 2002; Shohet and Paciuk, 2004; Lacasse and Sjöström, 2004; Gaspar and de Brito, 2008; Silva et al., 2016) have developed several service life prediction methodologies, intending to improve the knowledge regarding the deterioration processes and mechanisms of building and components, as well as providing relevant information concerning "how" and "when" to intervene (Lacasse and Vanier, 1996). The knowledge regarding the real-life degradation phenomena, considering the simultaneous occurrence of several environmental degradation agents, is extremely important for different practitioners in the construction sector. The expected service life of a given element, when subjected to a specific set of environmental exposure conditions, is a valuable information that can be used by: i) manufacturers, to establish warranty periods for external claddings; ii) designers, to select and prescribe the most suitable material for a given application; and iii) facilities managers, to allow adopting more rational maintenance policies, optimizing the use of funds and resources, as well as improving the quality and durability of buildings and components.

In this study, a new approach is proposed to predict the degradation process of ceramic claddings over time. The buildings façades are used as a case study, since they are the first layer of protection against the aggressive deterioration agents, and therefore, these elements are more prone to degradation (Silva et al., 2015a). The degradation phenomena present a high level of randomness and uncertainly, and their stochastic nature should be recognized in the building management system research.

Currently, Markov-based models are the most common stochastic technique applied to modelling the deterioration of assets (Butt et al., 1987; Cesare et al., 1992; Silva et al., 2015a). These models are considered intuitive and computationally inexpensive, due to the memoryless property, which allows estimating the future performance only based on 
the current performance, which is particularly relevant when limited information is available (Ferreira et al., 2017). In this study, a Petri-net modelling technique is used to model the deterioration of ceramic claddings, considering the isomorphism between Markov chains and stochastic Petri nets. Petri net models have been successfully applied to model dynamic systems in several areas, due to their flexibility and high accuracy in modelling complex phenomena (van der Aalst, 2002; Tang et al., 2008; Cheng et al., 2013; Chen et al., 2014; Uzam et al., 2016; Al-Ahmari, 2016; Yianni et al., 2016; Rinke et al., 2017).

The durability and service life of buildings, and especially external claddings, are strongly influenced by the environmental exposure conditions. In this study, a stochastic Petri-net formalism is also applied with the purpose of analysing the influence of different environmental degradation agents in the overall degradation of ceramic claddings over time. For that purpose, a sample of 195 ceramic claddings, located in Lisbon (Portugal), is analysed using in situ visual inspections to quantify deterioration. The deterioration state of each cladding analysed is defined based on a discrete scale divided into five condition levels, ranging between condition A (with no visible degradation) to condition $\mathrm{E}$ (most serious degradation condition, corresponding to generalised degradation).

This study can be divided in three parts. In the first one, a deterioration stochastic Petri net based model is proposed and calibrated using the overall sample. In the second part, the original sample is divided according to the environmental exposure conditions, evaluating the influence of these conditions on the deterioration process of ceramic claddings. For that purpose, four environmental exposure factors are analysed: exposure to damp; distance from the sea; orientation; and the combined action of rain and wind. Finally, in the third part, an independence analysis is performed, using the one-way ANOVA test.

In the proposed stochastic Petri-net model, the degradation phenomenon is modelled as a sequential dynamic system (in which the maintenance actions are not considered, 
assuming that each cladding only transits from a given condition to a more unfavourable one) and a set of probabilistic distribution functions are used to model the transitions times between degradation condition states. Compared to other stochastic modes, Petri Nets have greater flexibility under a consistent formalism. On the one hand, the flexibility allows for the modelling of all aspects of the lifecycle (e.g. inspection, maintenance, and repair) in a consistent framework. The use of a consistent formalism allows for faster development and simpler maintenance of software. This method allows using several distribution functions to model the time of transitions between condition states, which is a major advantage when compared to Markov chains, which only allow using the exponential distribution. The optimization of the models' parameters is performed using a Monte Carlo and Genetic Algorithm optimization framework, in which the fitness function is defined based on the concept of maximizing the likelihood. The results obtained show the relevant impact of the environmental exposure conditions in the service life of external ceramic claddings. This information allows identifying the deterioration rate of ceramic claddings according to their location and exposure conditions, thus improving the decision-making regarding the design, execution, maintenance and repair of these claddings.

The study is structured as follows: in the following section, a basic background concerning the Petri net formalism is described; the methodology proposed to predict the life-cycle performance of ceramic claddings is described in Section 3; in Section 4, a oneway ANOVA test is performed; and finally, a discussion of the results is presented in Section 5 and the main conclusions are provided in Section 6.

\section{Background}

The use of Petri nets has increased in the last years, essentially due to their flexibility to model dynamic systems in different areas of knowledge (van der Aalst, 2002; Tang et al., 2008; Cheng et al., 2013; Chen et al., 2014; Uzam et al., 2016; Al-Ahmari, 2016; Yianni 
et al., 2016; Rinke et al., 2017). Petri net models provide a graphical and mathematical formalism; the graphical representation allows describing the problem in an intuitive way; while the mathematical formalism allows developing efficient algorithmic to solve complex problems. Furthermore, the different variants of Petri net models that have been developed over the years are all related through the basic net formalism which they are built upon. This flexibility allows meeting the needs in different applications domains and the incorporation of many rules in the model to accurately simulate complex situations, still keeping the model size within manageable limits (Girault and Valk, 2013).

The original concept of Petri nets was developed by C. A. Petri (Petri, 1962). A Petri-net is a particular kind of graph with an initial state called the initial marking, $M_{0}$ (Peterson, 1977; Murata, 1989; Schneeweiss, 2004). A Petri-net comprises two kinds of nodes: i) places, which represent resources or particular states of the system; and ii) transitions, which represent an action or an event changing the state of the system. Both nodes are linked by directed edges (arcs). An arc connects a place with a transition or vice-versa. Each place has the ability to store a varying number of tokens. Tokens represent the present state of the system and their distribution over the places is called its marking. The movement of the tokens between places and the evolution of the system from one state to another is governed by the firing of transitions. A transition is enabled to fire when the number of tokens in all input places is greater than or equal to the weight of the pre-condition arcs (directed edges that link the input places to the transitions). These two elements (tokens and transitions) are responsible for modelling the dynamic behaviour of the system.

Figure 1 shows a basic example of a Petri-net, which illustrates a Petri-net before and after a transition fires. The net is composed of three places (denoted by circles), one transition (identified by a rectangle), and tokens (represented by black dots) within the places. Places and transitions are linked by arrows which indicate the direction that the 
tokens should move. Places $P_{1}$ and $P_{2}$ are the input places of transition $T_{1}$, while the place $P_{3}$ is the output of transition $T_{1}$. In Figure 1 a transition $T_{1}$ is considered ready to fire once the pre-conditions are verified. After the transition fires, the number of tokens of the preconditions are removed from the respective input places and the number of tokens of the post-conditions (arrows that link the transition to the output places) are added to the respective output places - Figure $1 b$.

\section{$3 \quad$ Research objectives}

The aim of this work is to develop probabilistic deterioration models for building facades that incorporate the impact of local environmental factors. To achieve this, the following objectives were defined: (i) propose a flexible deterioration model based on Petri-nets; (ii) evaluate the dependence between performance and a set of environmental conditions using ANOVA; (iii) propose updated deterioration models, taking into account the results of ANOVA. Finally, the proposed models are applied to the façade dataset, to predict the future performance of these facades and the impact of different exposure classes on their degradation condition over time.

\section{Deterioration Petri net model}

The deterioration process can be modelled using Petri-nets, through the definition of a linear sequence of places and timed transitions, where each place represents a condition state of the classification system adapted and the timed transitions define the movement between conditions states (Andrews, 2012; Yianni et al., 2016). The position of the token in the network indicates the present condition of the element. Figure 2 illustrates the Petri net structure used to model the deterioration process of ceramic claddings over time. 
The model is composed of five places $\left(P_{1}\right.$ to $\left.P_{5}\right)$ and four transitions $\left(T_{1}\right.$ to $\left.T_{4}\right)$. Place $P_{1}$ represents the best condition state and place $P_{5}$ the worst condition level. Since maintenance is not considered in this study, the condition level of the cladding deteriorates continuously over time until it reaches the worst condition level defined in the performance scale. Timed transitions are used to model the sojourn time in each condition level (i.e. the time the element spends in condition level $i$ before moving to condition level $i+1$ ).

\subsection{Timed transitions}

Although not originally included in Petri-nets, timed transitions allow including the time dependence in these models. The methodology used herein is based on the stochastic Petri nets formalism proposed by Dugan et al. (1984). A firing rate is assigned to each transition that can be modelled by any probabilistic distribution.

Since there is limited information on the statistical properties of the deterioration process of ceramic claddings, a set of five probabilistic distributions (Exponential, Weibull, Lognormal, Gumbel, and Normal distributions) are used to model the sojourn time in each condition level. Molly (1982) has proven that there is an isomorphism between bounded Petri-net with exponentially distributed transition rates and a finite Markov process. This property can be used to validate the deterioration Petri-net model proposed, since Markov-based models are the most commonly used stochastic technique in modelling deterioration. A Normal distribution was used since it is usually adequate to model the average of several independent random variables. If the ceramic cladding is seen as a set of areas deteriorating independently, then the average condition can be modelled as a normal distribution. However, a significant drawback of the normal distribution is the non-null probability of negative values which, in the present context, is not physically possible. Alternatively, the lognormal distribution can be used to model the times 
of transition avoiding negative values. If, on the other hand, the condition is mostly characterized by the deterioration of the most critical areas of the ceramic cladding, extreme distributions like the Weibull and Gumbel might be more adequate.

This modelling technique has several advantages when compared with the Markov chains. The graphical representation can be used to describe the problem intuitively. It is more flexible and has more capabilities than the Markov chains, it allows the incorporation of more rules in the model to simulate accurately complex situations and it keeps the model size within manageable limits. Moreover, this modelling technique is not restricted to the exponential distribution to simulate the time in the system. As main disadvantage, there are no closed form expressions for the probability distribution used and simulation techniques are required.

\subsection{Methodology implementation}

\subsubsection{Parameter estimation}

The probability density function that best describes the deterioration process is that resulting in higher probabilities of occurrence of the observed transitions. In order to identify the probability distribution that provides a best fit, parameter estimation is required. The parameters of the probability density function are fitted to history based on the concept of maximum likelihood used in the formulation proposed by Kalbfleisch and Lawless (1985). The likelihood is defined as the predicted probability of occurrence of the observed transitions:

$$
L=\prod_{i=1}^{n} \prod_{j=1}^{k} p_{i j}
$$

where $i$ is the condition level in the initial instant, $j$ is the condition level in the final instant, $n$ is the number of elements of the historical database, $k$ is the number of 
intervals between inspections, and $p_{i j}$ is the probability of transition from condition level $i$ to condition level $j$.

However, for numerical convenience, it is easier to work with the logarithm of the likelihood, Equation (2). The log-likelihood is used to simplify the computations and improve robustness of the algorithm.

$$
\log L=\sum_{i=1}^{n} \sum_{j=1}^{k} \log p_{i j}
$$

The probability of occurrence of the observed transitions, $p_{i j}$, is estimated by Monte Carlo simulation. This method allows obtaining good numerical approximations in situations where it is not feasible to obtain analytical solutions and can be used to consider the propagation of uncertainties during the claddings' service life. Therefore, using Monte Carlo simulation, the distribution of the final condition can be obtained and, consequently, the probability of the observed transition occurring can be computed.

The procedure used to compute the probability of occurrence of the observed transitions is illustrated in Figure 3. To each transition observed in the historical database, the algorithm has as input: time interval between observations, $\Delta t$, condition level in the initial instant, $i$, and condition level in the final instant, $j$. The condition level in the initial instant, $i$, is used to define the initial marking, $M_{0}$, of the Petri net; the time interval between observations, $\Delta t$, is the time horizon of the analysis; and the condition level in the final instant, $j$, is used to compute the probability of occurrence in the end of the procedure. The identification of the first transition to fire is performed through the initial marking, $M_{0}$, since once the Petri net defined for the deterioration model (Figure 2) is arranged in sequential manner, each condition level can only enable one transition. In the next step, the random sojourn time in the condition level is generated from the inverse CDF of probability distribution 
and the Petri net marking and time are updated. The process is repeated until the time horizon is reached. The procedure depicted is repeated for each transition observed in the historical database and the output of each sample is the condition index at the time horizon.

\subsubsection{Optimization}

The optimization of the parameters of the probability distributions is performed using Genetic Algorithms (GA). Genetic Algorithms (Holland, 1975) are an adaptive heuristic search algorithm inspired by natural evolution, such as inheritance, mutation, selection and crossover. Nowadays, GA are widely used in optimization problems. This technique is very robust and efficient for objective functions computed using Monte-Carlo simulations. GA use only information of the objective function, not requiring the computation of gradients, which greatly simplifies the problem and avoids numerical errors (Man et al, 1999; Morcous and Lounis, 2005).

In this study, the optimization of the parameters was performed using Genetic Algorithm available in MATLAB® (MatLab, 2016). The aim of the optimization algorithm is to find the parameters of the probability distributions which maximize the fitness function, $\log L=\max \left(\sum \sum \log p_{i j}\right)$. The parameters used in the Genetic Algorithm are the following:

- Size of the population: 50 individuals when the number of optimization variables is less than or equal to 5; and 200 individuals otherwise;

- Stopping criteria: the algorithm stops if the average relative change in the best fitness function value over 50 generations is less than or equal to $10^{-6}$;

- Mutation procedure was performed using the Gaussian algorithm implemented in MATLAB $®$, where the mutation is generated by adding a random number taken from a Normal distribution with mean zero. 
To ensure the validity of the models proposed in this study, it is relevant to examine the independence of the variables considered. For that purpose, a statistical comparison of the results is performed using an analysis of variance (ANOVA), and subsequent post hoc comparisons are made using a Tukey multiple comparison test.

The one-way ANOVA test (Neter et al., 1996; Wu and Hamada, 2000) compares the means between three or more of independent variables, determining whether any of those means are significantly different from each other, where the hypothesis is defined by:

$H_{0}$ : All group means are equal

$H_{1}$ : At least one group mean is different from the others

The statistical test can be validated through the comparison of the critical value of the $F$-ratio with the table $F$-value. The critical $F$-value is given by:

$$
F_{\text {crit }}=\frac{S S R /(k-1)}{S S E /(n \times k-k)}=\frac{M S R}{M S E}
$$

where $S S R$ is the between-groups sum of squares, $S S E$ is the within-groups sum of squares, $M S R$ is the between-groups mean squares, $M S E$ is the within-groups mean squares, $k$ is the number of group tested and $n$ is the number of observations in each group. If the critical $F$-value is greater than the table $F$-value or if the $p$-value is smaller than the significance level considered, the null hypothesis should be rejected. The table $F$-value has Fisher distribution with $k-1$ and $n \times k-k$ degree of freedom.

When the null hypothesis is rejected, it is concluded that at least the mean of one group tested is statistically different from the others. However, the ANOVA test does not indicate which groups are statistically different from each other. To determine that, a Tukey multiple comparison test (Hochberg and Tamhane, 1987) must be performed. This test is based on the studentized range distribution and it is optimal for procedures with 
equal sample sizes. The Tukey test compares all pairwise possible between groups and it can be stated that the groups compared are statistically different and the null hypothesis is rejected if the following relationship is verified:

$$
\frac{\left|\overline{y_{l}}-\overline{y_{j}}\right|}{\sqrt{M S E \cdot\left(\frac{1}{n_{i}}-\frac{1}{n_{j}}\right)}}>\frac{1}{\sqrt{2}} \cdot q(\alpha ; k ; n \times k-k)
$$

where $\overline{y_{l}}$ and $\overline{y_{J}}$ are the mean of the group $i$ and $j$, respectively; MSE is the withingroups mean squares obtained from the one-way ANOVA test; $n_{i}$ and $n_{j}$ are the number of observations in group $i$ and $j$, respectively; and $q(\alpha ; k ; n \times k-k)$ is the upper $100 \times$ $(1-\alpha)$ th percentile of the studentized range distribution with parameter $k$ and $n \times k-k$ degrees of freedom and a significance level of $\alpha$.

\section{$6 \quad$ Results and discussion}

The deterioration Petri net based method described in Section 4 is applied to model the deterioration process over time of a sample of 195 ceramic claddings located in Lisbon, Portugal. The degradation state of each cladding in the dataset was analysed based only on in situ visual inspections. Each place illustrated in Figure 2 represents one of the five deterioration conditions of ceramic claddings, proposed by Bordalo et al. (2011) and Silva et al. (2016).

The application of the deterioration Petri-net model is performed in two phases. In the first one, the complete sample is analysed, evaluating among the five probabilistic distribution functions mentioned before. In the second phase, the original sample is divided according to the environmental characteristics, and the most relevant characteristics to explain the degradation of ceramic claddings, namely exposure to damp, distance from the sea, façades orientation and wind-rain action, are analysed. Finally, an inference analysis is performed to investigate the independency between the variables analysed (i.e. the environmental characteristics of the ceramic claddings). 
In this study, for each cladding considered in the historical database, only the initial and the final condition level are known. For the first one, it is assumed that, at time zero, the cladding is in the most favourable condition level (Level A, with no visible degradation) and the final condition level corresponds to the degradation condition observed at the inspection time.

\subsection{Classification of the degradation condition of ceramic claddings}

Various authors (Shohet et al., 2002; Shohet and Paciuk, 2004; Gaspar and de Brito, 2008) developed degradation scales to assess and characterise the deterioration condition of the buildings' façades. In this study, the deterioration condition of ceramic claddings is established by a discrete scale, with five condition levels, ranging between A (most favourable condition, with no visible degradation) to E (worst case scenario, with generalised degradation) (Bordalo et al., 2011). In this scale, level D corresponds to the end of service life of ceramic claddings, considering that, once the cladding reaches this state, a maintenance action must be performed. The scale adopted is based on the evaluation of the physical and visual condition of the sample analysed, according to the defects observed, their extent and severity. In this study, the defects observed in ceramic claddings are divided in four categories: i) visual defects; ii) cracking; iii) joint deterioration; and iv) adhesion failure. The overall degradation level of ceramic claddings is evaluated through a numerical index (Gaspar and de Brito, 2008, 2011), called as severity of degradation, Sw, which is obtained through the ratio between the extent of the façades degradation, weighted as a function of the degradation level and the severity of the defects, and a reference area, equivalent to the whole area of the façade degraded to the maximum possible level (Equation (5)).

$$
S_{w}=\frac{\sum\left(A_{n} \times k_{n} \times k_{a, n}\right)}{A \times k}
$$


Where $S_{w}$ is the degradation severity of the coating, expressed as a percentage; $k_{n}$ is the multiplying factor of anomaly $n$, as a function of their degradation level, within the range $K=\{0,1,2,3,4\} ; k_{a, n}$ is a weighting factor corresponding to the relative weight of the anomaly detected $\left(k_{a, n} \in R+\right) ; A_{n}$ is the area of coating affected by an anomaly $n ; A$ is the façade area; and $k$ is the multiplying factor corresponding to the highest degradation level of a coating of area $A$.

The coefficient $k_{n}$ allow weighting the severity of the defects detected in the cladding, where the value zero is adopted for defects in condition $A, 1$ for defects in condition $\mathrm{B}$ and so on, until 4 for condition $\mathrm{E}$. The coefficient $k_{a, n}$ corresponds to the weighting coefficient associated with the relative importance of each defect, according to their severity, repair cost, influence in the overall degradation of the cladding, propensity to cause other defects and risk for the owners and users' safety. Table 1 shows the defects considered in this study, the qualitative and quantitative scales adopted, and the weighting coefficients applied in Equation (5). Figure 4 provides some illustrative examples of the visual appearance and some defects observed in ceramic claddings in the different degradation levels.

\subsection{Probabilistic analysis of the degradation of ceramic claddings over time}

Table 2 shows the optimised estimation parameters obtained for the distribution functions analysed, as well as the respective likelihood value. Table 3 presents the number of observed and predicted ceramic claddings in each condition level for each probability distribution function, with the relative error associated with the estimates. The green and red cells indicate the distributions with lower and higher relative errors, respectively, for each condition level.

One of the main conclusions that can be drawn, based on these results, it is that twoparameter distributions (Weibull, lognormal, Gumbel and normal) show a higher agreement to the dataset than the exponential distribution (Table 2). The accuracy of the five 
distribution functions in the description of the behaviour of the historical data can be evaluated through the results in Table 3, which compare the number of observed and predicted claddings in each degradation condition. The quality of fit of the proposed model can be evaluated by comparing the number of facades observed and predicted in each condition state, as shown in Figure 5. These results show that a reasonable fit is attained with all distributions, but also that larger relative errors might result for Levels $\mathrm{A}$ and $\mathrm{E}$, due to the smaller sample size.

Regarding the relative error (Table 3), in $76 \%$ of the cases the error is lower than $10 \%$ (and in $40 \%$ of the cases is below 5\%). The extreme condition levels (A and E) are those with the highest errors (between 4\% and 30\%); in Level A, the highest errors occur for the normal (24.3\%) and Weibull (11.2\%) distributions; in Level E, the highest errors occur for the normal (29.1\%), Weibull (23.0\%) and Gumbel distributions (21.3\%). It is important to notice that, in the sample analysed, only $8 \%$ of the cases studied belong to level A and only $2 \%$ to level E. Therefore, the model is naturally less accurate for the conditions for which less information exists. Analysing the mean relative error for all condition levels, the lognormal distribution shows the lowest overall mean relative error $(5.4 \%)$, followed by the exponential distribution (7.7\%) and the Weibull distribution (with an overall mean relative error of $8.9 \%$ ).

Silva et al. (2015b) applied Markov chain models to analyse in a probabilistic way the degradation of ceramic claddings over time, based on the same dataset used in this study. The values of the parameters obtained by Markov chains and with the exponential distribution through Petri nets are rather similar (as shown in Table 4). The highest differences occur for the mean and standard deviation of the parameter $T_{4}$ (concerning the transition between Level D to Level E). This occurs due to the low number of elements in Level E. The differences obtained in the other parameters are due to sampling errors associated 
with the Monte Carlo simulation. The results obtained by Petri-nets confirm that there is an isomorphism between both models and the Petri-net formalism is suitable to evaluate and describe the degradation of ceramic claddings.

Figure $6 \mathrm{a}$ presents the mean future condition profile over time for all probability distribution functions analysed. The condition profile obtained for the exponential distribution is quite distinct from the other four profiles; this distribution shows a profile with a simple parabolic shape without inflection points. The probabilistic curves obtained by Weibull, Gumbel and normal distributions are very similar throughout the time horizon considered, and small changes of the concavity are visible when there is a transition in the condition level. The profile obtained when considering a lognormal distribution is a mixture of the two types of profiles referenced above. The profile of the lognormal distribution is very similar to the profiles of the Weibull, Gumbel and normal distributions during the first transitions (level A to B, level B to $\mathrm{C}$ and level $\mathrm{C}$ to $\mathrm{D}$ ). The main difference lies in the transition between levels D and E, where the profile shows more likeness to the profile of the exponential distribution. In terms of the dispersion of the results (Figure 6b), the values obtained are low, and the two-parameter distributions present lower dispersion values over the time horizon than the exponential distribution.

Figure 7 shows the probability distribution of all degradation condition levels over time. The differences between the probability distribution functions, described above, are also visible in these plots. Based on the results obtained, the following conclusions can be drawn:

- For level A, the predicted probabilities for all distribution functions are similar, beginning with a probability equal to 1 in instant zero, decreasing over time, and at year 30, the probability of a ceramic cladding belonging to level $\mathrm{A}$ is close to zero (Figure 7a). Furthermore, between years 5 and 7, the probability of a ceramic cladding belonging to either level A or B is practically the same, i.e. whatever the 
distribution chosen to describe the process of deterioration, the results show that the transition between level A to B occurs during this time interval;

- For level B, the differences between the distribution functions analysed is more visible; the maximum probability of a ceramic cladding belonging to level B occurs between years 12 and 16 (however, this peak is $15-20 \%$ lower when the exponential distribution is used - Figure 7a). According to the exponential distribution, the transition from level B to C occurs around year 22, while with the twoparameter distribution functions it between condition $\mathrm{B}$ and $\mathrm{C}$ occurs six years later (around year 28);

- The maximum probability of a ceramic cladding belonging to level $\mathrm{C}$ (Figure $7 \mathrm{~b}$ ) is 0.50 for the exponential distribution, while for the other distributions this value varies between 0.70 and 0.80 . Once the maximum probability is achieved, the slope of the exponential distribution is less pronounced, when compared with the other distributions. The transition between levels C and D occurs around year 54 for the two-parameter distributions and 13 years later (around year 67) for the exponential distribution;

- The higher differences between the results of the various distributions are obtained in level D (Figure 7b) and E (Figure 7c). Exponential and lognormal distribution functions, during the time horizon analysed, never show a transition between these two condition levels. For Weibull and normal distributions, the transition between these condition levels occur around year 84 and for the Gumbel distribution this transition occurs around year 90 .

The results obtained reveal that exponential and normal distributions are not the most appropriate functions for the description of the degradation phenomena of ceramic claddings, especially in the description of the transition between level D to E. The lack of accuracy of 
the exponential distribution can be explained with a limitation of the distribution, since it has only one parameter, which can compromise its adequacy to model the deterioration process. For the normal distribution, the inadequate adjustment to the dataset is related with the low number of claddings in level E (only 3 elements, Table 3 ). The results show that the low number of observations is insufficient for the normal distribution to properly estimate the parameters that best describe the deterioration process. However, it is stressed that the time horizon considered in this study, and presented in the analysis of Figure 6, is not realistic for ceramic claddings, since this type of cladding is usually subjected to maintenance actions around year 50 (or at level D, which represents a minimum accepted level of performance); until this time, i.e. the expected end of service life of ceramic claddings, there is a good fit of the normal distribution to the description of the degradation conditions of ceramic claddings.

From the available data, the Weibull distribution seems to result in a better fit to the observed results and will be used in the subsequent analysis. Nevertheless, it must be noted that the data available at this time are limited, and consequently, larger datasets might show that this is not always the most adequate distribution. In particular, both the Gumbel and the lognormal distribution result in reasonable fit and should be considered in future works.

As stated before, level D corresponds, in this study, to the minimum accepted performance level, and thus to the end of service life of ceramic claddings. According to the Petri net based model proposed in this study (adopting one of the two-parameter distributions normal, lognormal, Weibull and Gumbel), the ceramic claddings have a maximum probability of transition to level D around year 54. This age can be considered as the expected service life of ceramic claddings, for the sample analysed, and according to the proposed model. This value is coherent with the empirical knowledge and the literature related with the durability of this type of cladding: i) according to Silva et al. (2016), the estimated service life of adhe- 
sive ceramic wall claddings varies between 46 and 50 years; ii) Galbusera et al. (2015) proposed an average service life around 51 years for ceramic claddings; iii) BMI (2001) suggested that the estimated service life of ceramic claddings varies between 25 and 55 years (with an average value of 45 years); and iv) Gaspar (2017) proposed an estimated service life of 49 years for external ceramic claddings.

\subsection{Independence analysis}

A one-way ANOVA was performed in order to check whether the complete sample and the twelve variables that it was divided in are independent, i.e. whether for a determined time horizon the final condition level obtained is influenced by the different variables that the complete sample was divided in. The ANOVA test results are presented in Table 5. The statistical test was performed for five different time horizons using 50,000 samples in the simulation process.

As mentioned before, the test can be validated through the comparison of the critical value of the $F$-ratio (Table 5) with the table $F$-value or through the comparison of the $p$-value with the established significance level. For a significance level of 0.05 , the table $F$-value is equal to 1.752 .

Through the analysis of the results obtained, it is possible to see that for the five time horizons tested the null hypothesis is rejected. This result shows that at least one group mean is statistically different from the others, but it does not tell which groups are statistically different from the others. To determine that, a Tukey test was performed.

The Tukey test compares all pairwise possible between groups and it can be stated that the groups compared are statistically different and the null hypothesis is rejected if the relationship of Equation (4) is verified. The value of the right side of Equation (4) is constant for all analyses and equal to 3.12. The values of the left side are presented in 
Table 6. Green cells identify the pairwise where the null hypothesis is not rejected.

As in the probabilistic analysis, the results obtained in the statistical test can be divided in two parts. In the first part of the analysis, the complete sample was compared with each subset. The results show that the mean of intermediate situations (intermediate distance from the sea, SI, and moderate wind-rain action, WM) are statistically closer to the overall sample. In the other situations, the differences between the mean of the groups are statistically significant showing that the variables are independent.

In the second part of the analysis, a comparison with each family of variables was performed. The results show that for year 10 the mean of intermediate distance from the sea (SI) and close to the sea (SC) are statistically close, and for year 40 there are significant dependence between variables orientation - east $(\mathrm{OE})$ and orientation - north $(\mathrm{ON})$ and orientation - west (OW) and orientation - south (OS). In the remaining situations, the differences between the mean of the groups are statistically significant showing that the variables are independent.

The different environmental factors have significantly different impacts on the performance of the facades during their life. The results of the ANOVA seem to indicate that the greater impact of environmental conditions is in the first 20 years of the life of the façade, except for orientation, which has a relatively uniform impact during the entire life. This is consistent with the expected deterioration mechanics, as orientation mostly affects the slow evolving damage associated with exposure to UV, while the other exposures influence water and chloride content which impact deterioration much faster. The impact during the first years of life is particularly relevant under aggressive exposures (e.g., high exposure to damp, less than $5 \mathrm{~km}$ from the sea, high exposure to wind-rain), showing that for these facades the change from condition $\mathrm{A}$ to $\mathrm{B}$ and $\mathrm{C}$ is much faster than for the entire population. 


\subsection{Impact on environmental conditions on deterioration}

The typical degradation mechanisms that lead to the premature degradation of external claddings include climatic or atmospheric weathering factors, such as UV radiation, temperature, moisture, air constituents and marine environments (Lewry and Crewdson, 1994; Shohet and Paciuk, 2006). Naturally, ceramic claddings are subjected to different environmental exposure conditions, which strongly influence their deterioration rate and their expected service life. In this sense, this study intends to evaluate the influence of four environmental conditions (exposure to moisture, distance from the sea, orientation and UV radiation and wind-rain action) in the description of the overall degradation of ceramic claddings over time.

The results obtained in the analysis, according to the various environmental characteristics are shown in Table 7 and Figure 7 . Table 7 shows the probability of belonging to each degradation condition, according to the variable considered and Figure 7 presents the predicted future condition over time for these variables. The predicted future condition profile for each variable is obtained through the distribution that presents the minimum normalized log-likelihood value (Table 7). The normalized log-likelihood is obtained as the ratio between the likelihood and the number of elements in the sample - Equation (6). The obtained value represents the expected log-likelihood of a single element in the model.

$$
\hat{l}=\frac{\log L}{n}
$$

where $n$ is the number of elements in the dataset.

\subsubsection{Distance from the sea (exposure to marine environments and sea salts)}

The interaction between the salt spray from sea and building materials has been extensively analysed in the literature (Brocken and Nijland, 2004; Lubelli et al., 2004). The presence of salt, usually on the external surfaces of the facades due to the action of wind containing sea spray (Hossain et al., 2009), causes the occurrence of defects and leads to the progressive 
deterioration of porous materials, such as ceramic claddings. Severe exposure to sea spray, in coastal areas, leads to various defects, e.g. efflorescence, exfoliations or spalling (Sena da Fonseca et al., 2013). Figure 9 shows an illustrative example of the degradation condition of a ceramic cladding located less than $2 \mathrm{~km}$ from the sea, due to the influence of the sea spray. In this study, the ceramic claddings are divided in three categories regarding their distance from the sea: i) sea front areas (less than $1 \mathrm{~km}$ ); ii) in coastal areas (between 1 and $5 \mathrm{~km}$ from the sea); and iii) away from the sea (more than $5 \mathrm{~km}$ ). The samples for the variable less than $1 \mathrm{~km}$ from the sea, between 1 and $5 \mathrm{~km}$, and more than $5 \mathrm{~km}$ include 77, 62 and 56 elements, respectively.

As expected, the influence of the sea in the overall condition of the claddings is evident. The claddings located near the sea tend to belong to the most unfavourable conditions levels, levels $\mathrm{D}$ and $\mathrm{E}(\mathrm{P}=71.7 \%)$. This tendency decreases with the distance from the sea, and the probability of a cladding belonging to the most unfavourable conditions (levels D and E) are $62.8 \%$ and $29.9 \%$ for the intermediate distance from the sea and for claddings located more than $5 \mathrm{~km}$ from the sea, respectively. Claddings located more than $5 \mathrm{~km}$ from the sea, less prone to the presence of sea spray, have a higher probability of belonging to the most favourable conditions (levels A and B) for a longer period of time.

\subsubsection{Exposure to moisture}

The exposure to moisture is one of the main causes of several deterioration mechanisms that occur in buildings and components. External ceramic claddings are particularly exposed to this degradation agent, which when associated with salt leaching, can cause aesthetic degradation (e.g. efflorescence, glaze cracking, moisture stains, biological growth) and jeopardize the integrity of the claddings system (e.g. cracking, swelling, detachment, spilling and material loosing) (Charola, 2000; Rirsch et al., 2011; Madkour and Khallaf, 
2012; Silva et al., 2015a). Figure 10 shows some examples of the deterioration condition of ceramic claddings highly exposed to moisture.

Concerning exposure to moisture, the ceramic claddings analysed in this study are divided in two categories: i) low, for claddings in buildings located in urban context, more than $5 \mathrm{~km}$ from the sea and without the influence of dominant winds carrying sea salts; and ii) high, for buildings located closer to the sea or other humidity sources, under the direct influence of sea winds, and in areas with an average annual rainfall higher than $500 \mathrm{~mm}$ and an average annual relative humidity higher than $75 \%$. In the sample analysed, 111 case studies $(57 \%)$ present low exposure to moisture and $84(43 \%)$ high exposure to moisture.

The results obtained reveal that claddings with low exposure to moisture are more prone to remain longer in lower degradation conditions (levels A and B) and none of the claddings belong to level E. On the other hand, claddings with high exposure to moisture show more tendency to belong to the most unfavourable conditions, i.e. levels D and E, with a probability of $70.6 \%$.

\subsubsection{Orientation (exposure to UV radiation)}

Concerning the façades orientation, the sample analysed in this study was divided in the four main cardinal directions: North; East; South; and West. The number of elements of each sample is 58, 40, 41 and 43, for north, east, south, and west, respectively.

Ceramic claddings facing west remain a longer period of time in levels A and B, with a probability of $50.2 \%$. On the opposite, ceramic claddings facing south are more prone to belong to level $\mathrm{E}(\mathrm{P}=4.1 \%)$, followed by claddings facing north $(\mathrm{P}=1.9 \%)$.

Various studies (Gaspar and de Brito, 2008; Silva et al., 2015a, 2016) refer that, in Portugal, façades facing north and west are more prone to degradation, thus presenting higher degradation levels; north is colder (with lower periods of UV radiation) and more 
exposed to the action of moisture; and west has the highest probability of the combined occurrence of wind and rain. On the other hand, in Portugal, claddings facing south are exposed to a longer period of time of UV radiation, which also contributes for the deterioration of ceramic claddings (Guan et al., 1997; Yiu et al., 2007). Therefore, the results obtained seem coherent, revealing that ceramic claddings facing north and south present higher degradation levels, even though due to different deterioration mechanisms and with different pathological occurrences.

\subsubsection{Wind-rain action}

Regarding the exposure to the wind-rain action, the dataset is divided in three categories, according to the height of the building and the density of ground occupation in the surrounding area (Silva et al. 2015a): i) low exposure, corresponding to low-rise buildings (up to 2-storey high), in densely populated areas, protected from prevailing winds by other buildings, adjacent hills or vegetation; ii) moderate exposure, corresponding to mediumhigh buildings, in populated urban areas, protected from prevailing winds by other buildings, adjacent hills or vegetation; and iii) high exposure, for buildings with more than 4 storeys or in open country or crossroads. The samples obtained for low, moderate and high exposure are composed by 45, 97 and 53 elements, respectively.

The results obtained by the Petri net based model reveal that claddings with high exposure to the combined action of wind and rain have a lower probability of belonging to the most favourable conditions levels, i.e. levels $\mathrm{A}$ and $\mathrm{B}(\mathrm{P}=26.3 \%)$. In the sample analysed, claddings with a moderate wind-rain exposure have the highest probability of belonging to levels A and $\mathrm{B}(\mathrm{P}=50.9 \%)$. Ceramic claddings with low and moderate exposures present an almost nil probability of belonging to condition $\mathrm{E}$.

According to the literature, the combined effect of wind and rain affects the way that raindrops reach the claddings surface, as well as the pattern of runoff flow along the 
cladding (Choi, 1999). Therefore, as expected, in the sample analysed, cladding with high exposure to the wind-rain action present higher degradation levels. On the other hand, in some situations, claddings with low exposure may not correspond to the ideal situation, since claddings protected from the rain are more prone to retain superficial dirt and other surface anomalies due to the deposition of particles. In a preliminary stage of the degradation process, in which the ceramic claddings only present visual or aesthetic anomalies, this factor can be relevant to justify the fact that claddings with moderate exposure are more prone to belong to level A (10.9\%), when compared with claddings with low exposure (P $=2.3 \%$ ). However, under current conditions, coatings more exposed to the combined action of wind and rain degrade more rapidly than those protected from this action. Figure 11 shows two case studies with moderate and low exposure to damp. Case study a) is 62 years old and shows a severity of degradation of $50 \%$, with moderate exposure to the wind-rain action; case study b) is 63 years old and presents a severity of degradation of $39.8 \%$, with low exposure to the wind-rain action, thus with a lower degradation level than case study a). It is stressed that, in this study, the influence of the environmental exposure conditions has been analysed individually. However, the degradation process is extremely difficult to model, since it has a multidimensional nature, where the deterioration of ceramic claddings occurs due to the simultaneous action of different factors.

\section{Conclusions}

In this study, the performance over time of ceramic claddings is analysed using a deterioration model based on stochastic Petri nets. The use of Petri nets has increased in the last years to model dynamic system in different fields of knowledge. This modelling technique has several advantages when compared with Markov chains or other stochastic approaches. Graphical representation can be used to describe the problem intuitively. Petri net models are more flexible and, unlike Markov chains, allow incorporating many rules 
in the model to accurately simulate complex situations and keep the model size within manageable limits. Moreover, this modelling technique is not restricted to the exponential distribution to simulate the time in the system. In some situations, the use of exponential distributions can result in a gross approximation of the system characteristics.

The Petri-net model described in this study does not consider the effects of maintenance actions. In fact, the age of the claddings, i.e. the time interval between observations, corresponds to the period of time since construction or the last maintenance action until the inspection time (final observation). Therefore, the deterioration phenomenon is modelled as a sequential dynamic system and the sojourn time in each condition level is defined as a random variable.

The deterioration rates were estimated from available historical date and five probability distributions (exponential, Weibull, Gumbel, lognormal and normal) were analysed to examine which distribution has a better fit to the historical date. The likelihood values of the five distributions are quite similar; however, the Weibull distributions shows a minor likelihood value and, consequently, a better fit to the historical data.

Concerning the independence analysis, the division of the original sample by environmental characteristics is important to evaluate the influence of these characteristics on the deterioration of the ceramic claddings over time. From the analysis of the influence of the environmental degradation agents, it is concluded that claddings in coastal areas, with high exposure to damp and wind-rain actions, or facing north show more tendency to belong to the most unfavourable condition levels, i.e. levels D and E (approximately a probability of $70 \%$ ). On the opposite way, claddings exposed to more favourable conditions (more protected from the aggressive environmental agents) are more prone to remain in lower degradation conditions (levels A and B) for a longer period of time. 
The Petri-net model proposed in this study can accurately describe the deterioration process of ceramic claddings, providing relevant information regarding the performance of these claddings according to their environmental exposure conditions during their service life. This study provides some guidance about the relationships between the service life of the ceramic claddings and their environmental exposure conditions. This information is extremely relevant to managers, insurers, owners and users, allow adopting more sustainable and durable solutions in the design stage and for the definition and implementation of reliable maintenance policies, enabling a more rational management of the European building stock.

\section{$8 \quad$ References}

Aikivuori, A. M. (1999). Critical loss of performance - what fails before durability. $8^{\text {th }}$ International Conference on Durability of Building Materials and Components, Vancouver, Canada, pp. 1369-1376.

Al-Ahmari, A. (2016). Optimal robotic cell scheduling with controllers using mathematically based timed Petri nets. Information Sciences, 329, 638-648.

Andrews, J. (2012). A modelling approach to railway track asset management. Proceeding of the Institution of Mechanical Engineers, Part F: Journal of Rail and Rapid Transit, 227(1), 56-73.

Beer, H.R., Kerber, C., Schläpfer, J.-L., Rieche, G., Unold, H., Wehrle, S. (2011). Longterm field studies and residual service life prediction of FPO roofing membranes. $12^{\text {th }}$ International Conference on Durability of Building Materials and Components, Porto, Portugal.

Bordalo, R., de Brito, Jorge, Gaspar, P. and Silva, A. (2011) Service life prediction modelling of adhesive ceramic tiling systems, Building Research and Information, 39(1): 66-78.

Brocken, H. and Nijland, T. (2004) White efflorescence on brick masonry and concrete masonry blocks, with special emphasis on sulfate efflorescence on concrete blocks, Construction and Building Materials, 18(5): 315-323. 
Building Maintenance Information (BMI) (2001). Life expectancy of building components. Surveyor's experiences of buildings in use: A practical guide. RCIS, Building Cost In-formation Service, UK.

Butt, A. A., Shahin, M. Y., Feighan, K. J., and Carpenter, S. H. (1987). Pavement performance prediction model using the Markov process. Number 1123 in Transportation Research Record. Transportation Research Board, National Research Council, Washington, D.C.

Cesare, M. A., Santamarina, C., Turkstra, C., and Vanmarcke, E. H. (1992). Modeling bridge deterioration with Markov chains. Journal of Transportation Engineering, 118(6): 820-833.

Charola, A. E. (2000) Salts in the deterioration of porous materials: An overview. Journal of the American Institute of Conservation, 39(3): 327-343.

Cheng, F., Li, H., Wang, Y. W., Skitmore, M., \& Forsythe, P. (2013). Modeling resource management in the building design process by information constraint Petri nets. Automation in Construction, 29, 92-99.

Chen, Y., Li, Z. and Barkaoui, K. (2014). Maximally permissive liveness-enforcing supervisor with lowest implementation cost for flexible manufacturing systems. Information Sciences, 256, 74-90.

Choi, E. C. (1999) Wind-driven rain on building facades and the driving-rain index. Journal of Wind Engineering and Industrial Aeronautics, 79(1-2): 105-122.

Dugan, J.B., Trivedi, K.S., Geist, R.M. and Nicola, V.F. (1984). Extended stochastic Petri nets: applications and analysis. Technical report, Duke University, Durham, NC, USA.

Ferreira, C., Neves, L. C., Silva, A., and de Brito, J. (2018). Stochastic Petri net-based modelling of the durability of rendering. Automation in Construction, 87, 96-105.

Galbusera, M.M., de Brito, J. and Silva, A. (2015) Application of the factor method to the prediction of the service life of ceramic external wall cladding. Journal of Performance of Constructed Facilities, 29(3): 04014086-1-10. 
Gaspar, P. and de Brito, J. (2008). Service life estimation of cement-rendered facades. Building Research and Information, 36(1), 44-55.

Gaspar, P. and de Brito, J. (2011). Limit states and service life of cement renders on façades. Journal of Materials in Civil Engineering, 23(10), 1396-1404.

Gaspar, P. L. (2017) End of the service life of ceramic cladding: Lessons from the Girasol building in Madrid. Journal of Performance of Constructed Facilities, 31(2), 04016088.

Girault, C. and Valk, R. (2013). Petri Nets for Systems Engineering: A guide to modelling, verification, and applications. Springer Science \& Business Media.

Guan, W.L., Alum, J., Liu, Z.J. and Yang, T. (1997) Performance of external tiled-wall systems under tropical weathering. Journal of Performance of Constructed Facilities, 11(1): 24-34.

Hochberg, Y. and Tamhane, A. C. (1987). Multiple Comparison Procedures. John Wiley \& Sons, Inc. Holland, J. H. (1975). Adaptation in natural and artificial systems: an introductory analysis with applications to biology, control, and artificial intelligence. U Michigan Press.

Hossain, K. M. A., Lachemi, M. and Şahmaran, M. (2009) Performance of cementitious building renders incorporating natural and industrial pozzolans under aggressive airborne marine salts, Cement and Concrete Composites, 31(6), 358-368.

Hovde, P. J. (2002). The factor method for service life prediction from theoretical evaluation to practical implementation. $9^{\text {th }}$ International conference on durability of buildings materials and components, Brisbane, Australia, Paper (Vol. 232).

Kalbfleisch, J. D. and Lawless, J. F. (1985). The analysis of the panel data under a Markov assumption. Journal of the American Statistical Association, 80(392), 863-871.

Lacasse, M. A. and Vanier, D. J. (1996) A review of service life and durability issues. $7^{\text {th }}$ International Conference on Durability of Building Materials and Components, Stockholm, Sweden, pp. 857-866. 
Lacasse, M. A. and Sjöström, C. (2004) Recent advances in methods for service life prediction of buildings materials and components - an overview. CIB World Building Congress, Canada, pp. 1-10.

Lewry, A. J. and Crewdson, L.F.E. (1994) Approaches to testing the durability of materials used in construction and maintenance of buildings. Construction and Building Materials, 8(4), 211-222.

Lubelli, B., Hees, R. and Groot, C. (2004) The role of sea salts in the occurrence of different damage mechanisms and decay patterns on brick masonry. Construction and Building Materials, 18(2): 119-124.

Madkour, F. S. and Khallaf, M. K. (2012) Degradation processes of Egyptian faience tiles in the step pyramid at Saqqara. Procedia - Social and Behavioral Sciences, 68: 63-76.

Man, K. F., Tang, K. S. and Kwong S. (1999). Genetic algorithms: concepts and designs. Springer-Verlag London, Great Britain.

MatLab (2016, July 18). Retrieved from http://www.mathworks.com/help/gads/how-the-geneticalgorithm-works.html.

Molly, M. K. (1982). Performance analysis using stochastic Petri nets. IEEE Transactions on Computers, C-31(9), 913-917.

Morcous, G. and Lounis, Z. (2005) Maintenance optimization of infrastructure networks using genetic algorithms. Automation in construction, 14(1), 129-142.

Murata, T. (1989). Petri nets: Properties, analysis and applications. Proceedings of the IEEE, 77(4), 541-580.

Neter, J., Kutner, M. H., Nachtsheim, C. J. and Wasserman, W. (1996). Applied Linear Statistical Models. Irwin Press.

Paulo, P. V., Branco, F., and Brito, J. de. (2014). BuildingsLife: a building management system. Structure and Infrastructure Engineering, 10(3), 388-397.

Peterson, J.L. (1977). Petri nets. Computing Surveys, 9(3), 223-252. 
Petri, C.A. (1962). Kommunikation mit Automaten. Bonn: Institut für Instrumentelle Mathematik, Schriften des IIM Nr. 3. Also, English translation, Communication with Automata. New York: Griffiss Air Force Base. Technical report RADC-TR-65-377, volume 1, supplement 1, 1966.

Rinke, N., von Gösseln, I., Kochkine, V., Schweitzer, J., Berkhahn, V., Berner, F., Kutterer, H., Neumann, I. \& Schwieger, V. (2017). Simulating quality assurance and efficiency analysis between construction management and engineering geodesy. Automation in Construction, 76, 24-35.

Rirsch, E., MacMullen, J., \& Zhang, Z. (2011). Evaluation of mortar samples obtained from UK houses treated for rising damp. Construction and Building Materials, 25(6), 2845-2850.

Schneeweiss, W.G. (2004). Petri net picture book (an elementary introduction to the best pictorial description of temporal changes). LiLoLe-Verlag GmbH, Germany.

Sena da Fonseca B., Simão, J.A.R. and Galhano C. (2013) Effect of coastal environment in clay facing bricks and roof tiles. $1^{\text {st }}$ Annual International Interdisciplinary Conference, AIIC 2013, $24-$ 26 April, Azores, Portugal, pp. 432-440.

Shohet, I., Puterman, M. and Gilboa, E. (2002). Deterioration patterns of building cladding components for maintenance management. Construction and Economics, 20(4), 305-314.

Shohet, I. and Paciuk, M. (2004). Service life prediction of exterior cladding components under standard conditions. Journal of Construction Management and Economics, 22(10), 1081-1090.

Shohet, I. and Paciuk, M. (2006) Service life prediction of exterior cladding components under failure conditions. Construction Management and Economics, 24(2), 131-148.

Silva, A., Neves, L. C., Gaspar, P. L., and de Brito, J. (2015a). Probabilistic transition of condition: render facades. Building Research \& Information, 44(3), 301-318.

Silva, A., Gaspar, P. L., de Brito, J., and Neves, L. C. (2015b). Probabilistic analysis of degradation of façade claddings using Markov chain models. Materials and Structures, 49(7), 1-22. 
Silva, A., de Brito, J. and Gaspar, P. L. (2016) Methodologies for service life prediction of buildings: with a focus on façade claddings. Series Green Energy and Technology, Springer International Publishing, Switzerland.

Tang, F., Guo, M., Dong, M., Li, M. and Guan, H. (2008). Towards context-aware workflow management for ubiquitous computing. In International Conference on Embedded Software and Systems (ICESS’08), 221-228.

Uzam, M., Gelen, G. and Saleh, T. L. (2016). Think-globally-act-locally approach with weighted arcs to the synthesis of a liveness-enforcing supervisor for generalized Petri nets modelling FMSs. Information Science, 363, 235-260.

Van der Aalst, W. M. (2002). Making work flow: On the application of Petri nets to business process management. In International Conference on Application and theory of Petri Nets (pp. 122). Springer Berlin Heidelberg.

Wu, C. F. J., and Hamada, M. (2000). Experiments: planning, analysis, and parameter design optimization. John Wiley \& Sons.

Yianni, P. Rama, D., Neves, L., Andrews, J. and Castlo, D. (2016). A Petri-Net-based modelling approach to railway bridge asset management, Structure and Infrastructure Engineering, 1-11.

Yiu, C. Y., Ho, D. C. W. and Lo, S.M. (2007) Weathering effects on external wall tiling systems, Construction and Building Materials, 21(3): 594-600. 


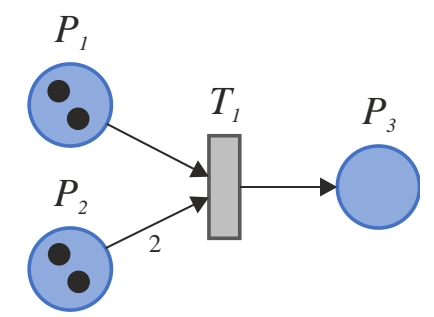

(a)

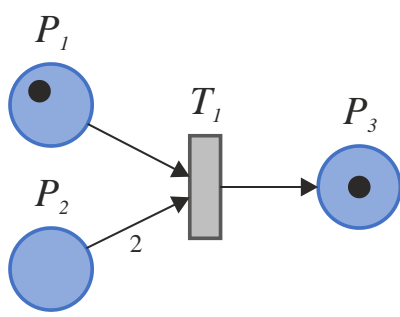

(b)

Figure 1. Example of a Petri net: (a) before and (b) after the fire of the transition. 


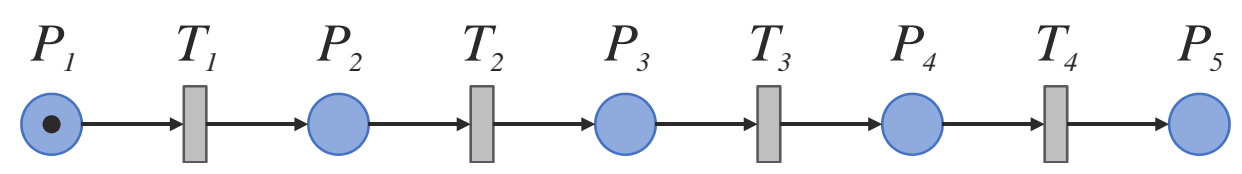

Figure 2. Petri net scheme of the deterioration process. 


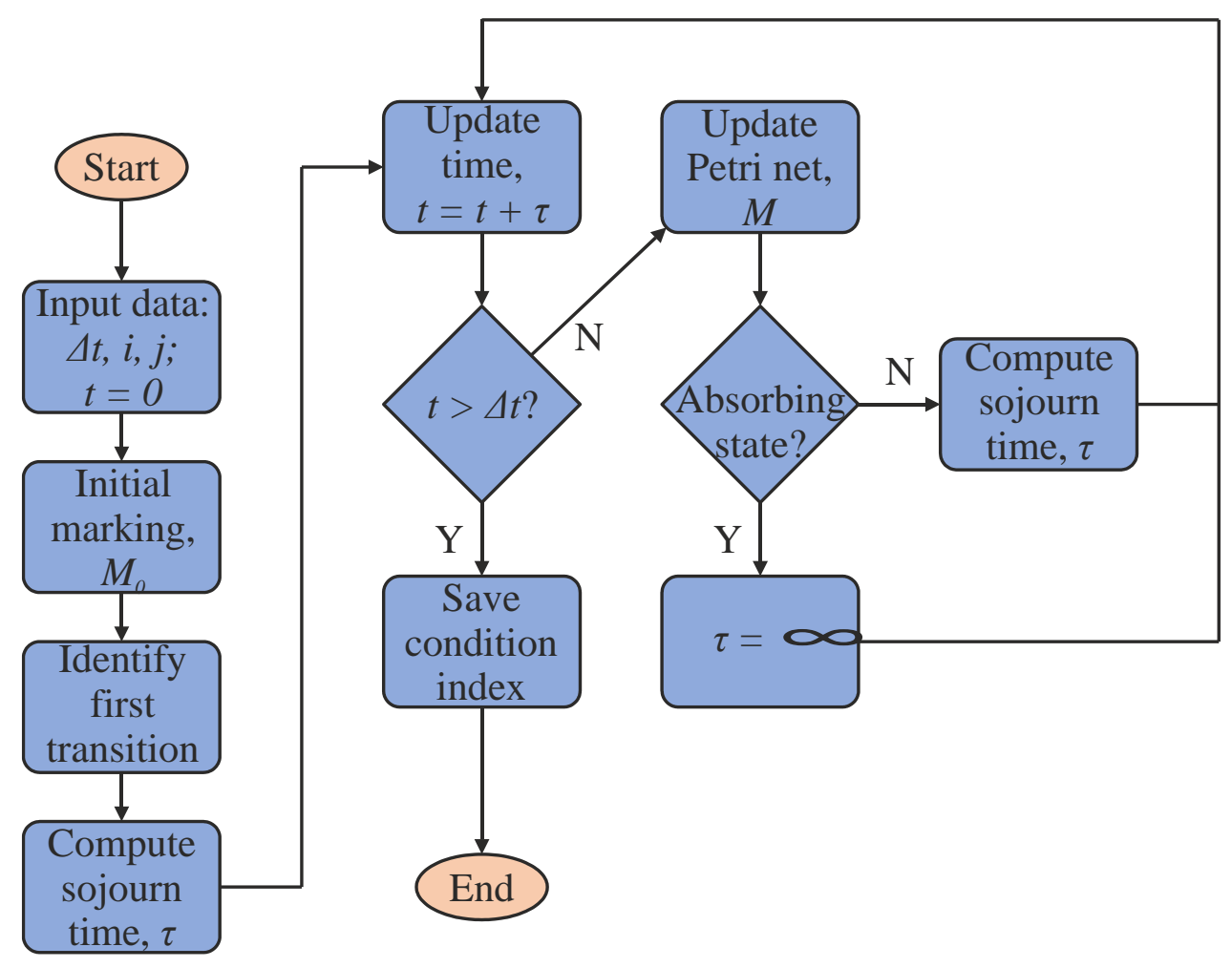

Figure 3. Procedure for computing the probability of occurrence of the observed transition. 


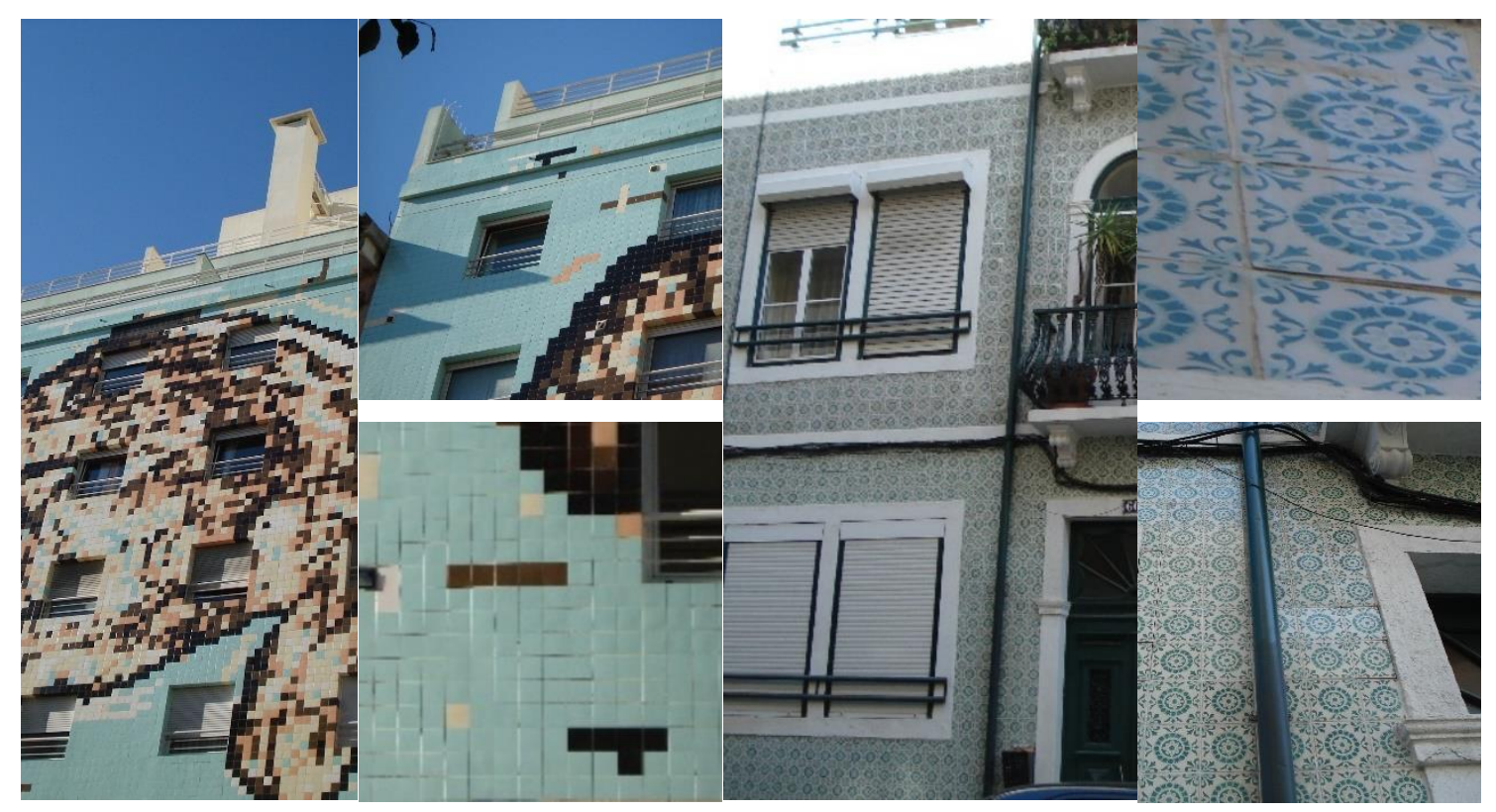

Condition B

Condition C

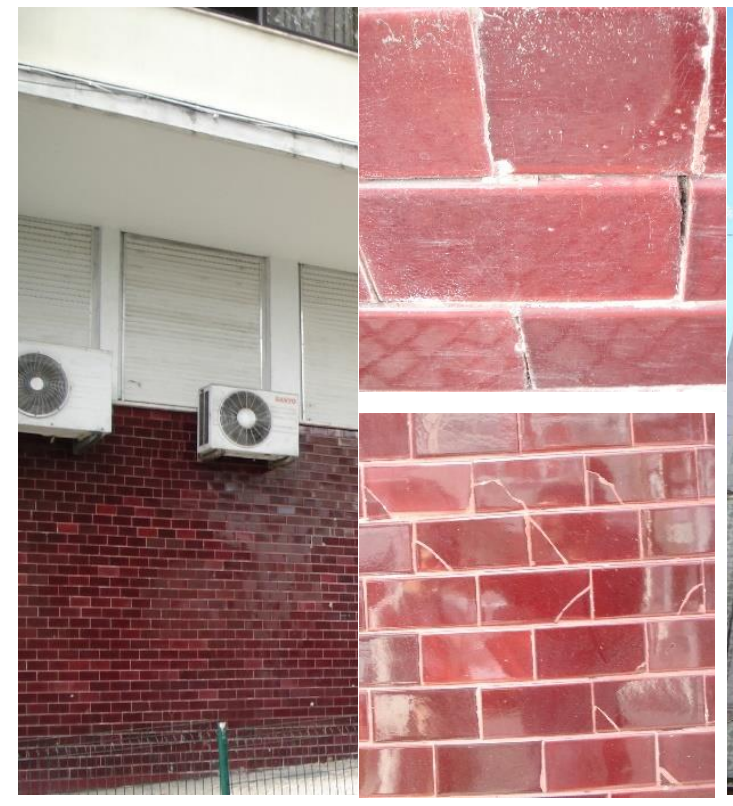

Condition D

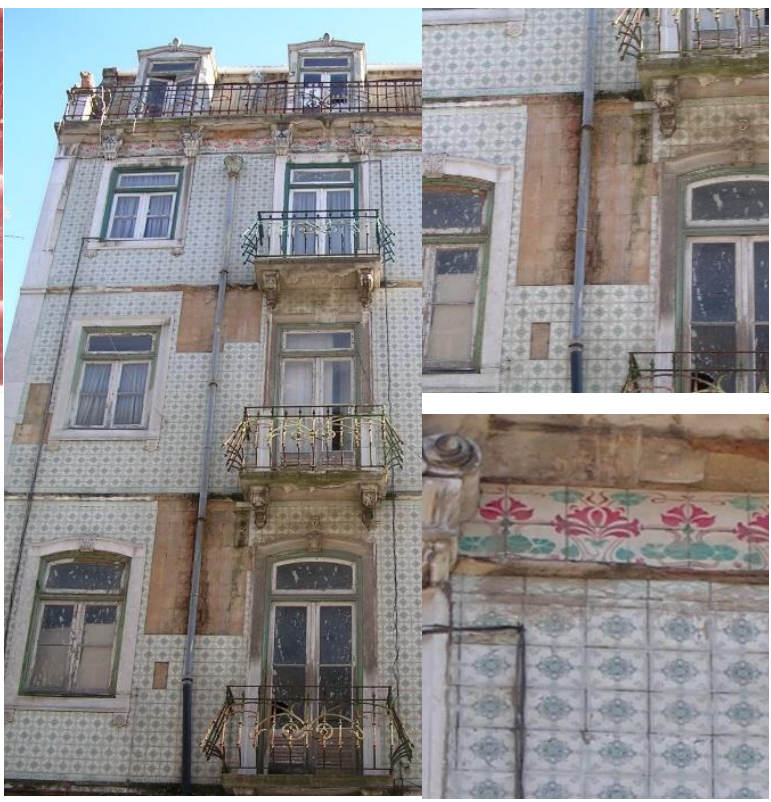

Condition E

Figure 4. Illustrative examples of the visual condition of ceramic claddings in each degradation level. 


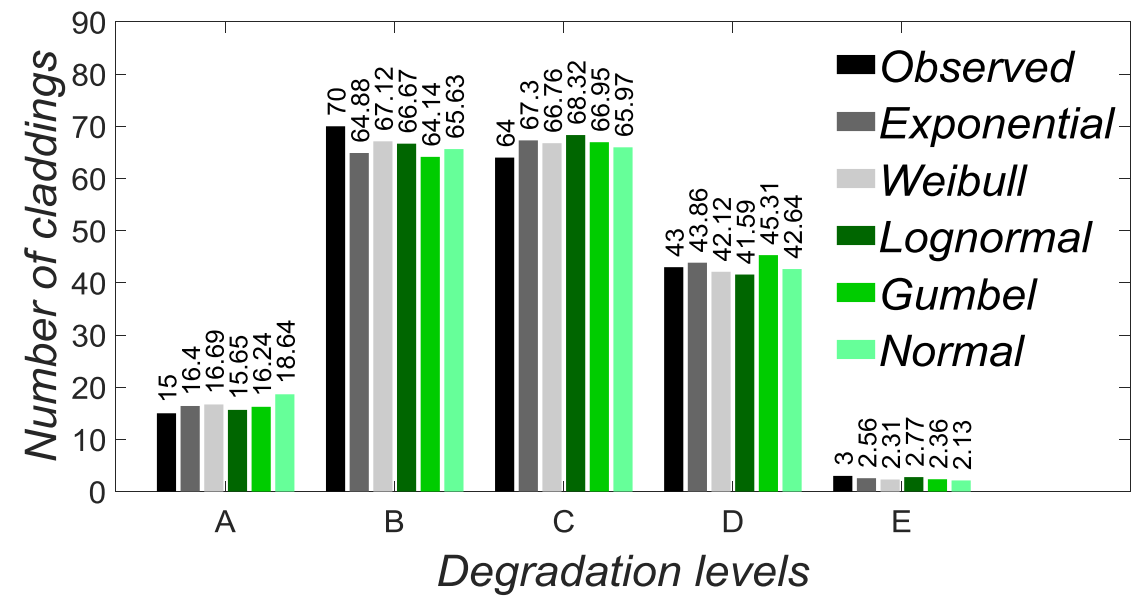

Figure 5. Comparison between the results predicted by the model (for the five probability distribution functions adopted) and the measured degradation state from the database (observed values). 


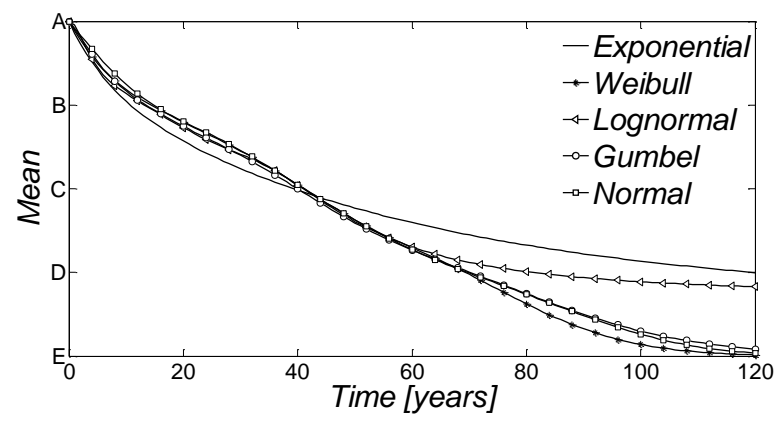

(a)

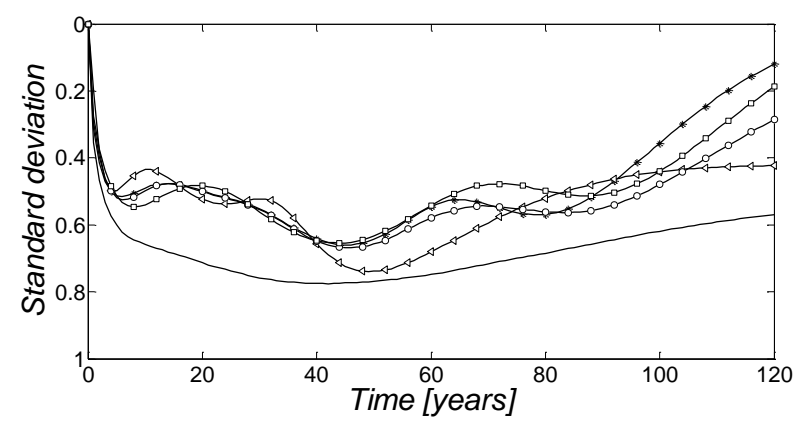

(b)

Figure 6. Comparison of the predicted future condition profile over time for all probability distribution analysed: (a) mean condition; (b) standard deviation of condition. Mean and standard deviation are computed considering a correspondence between the condition scale and an integer scale between 1 and 5 . 


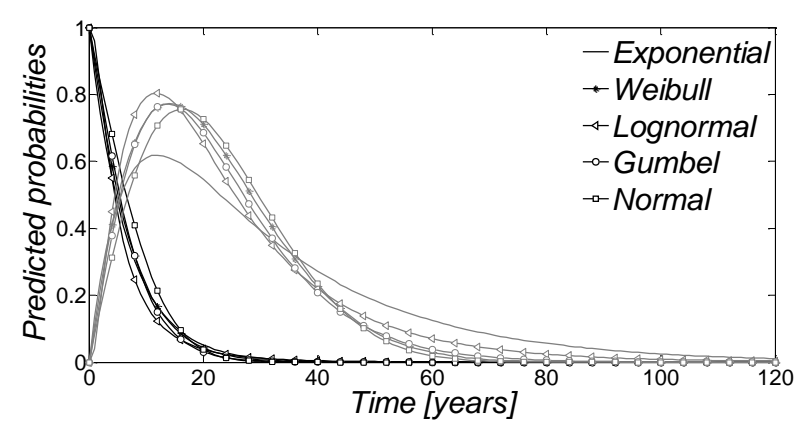

(a)

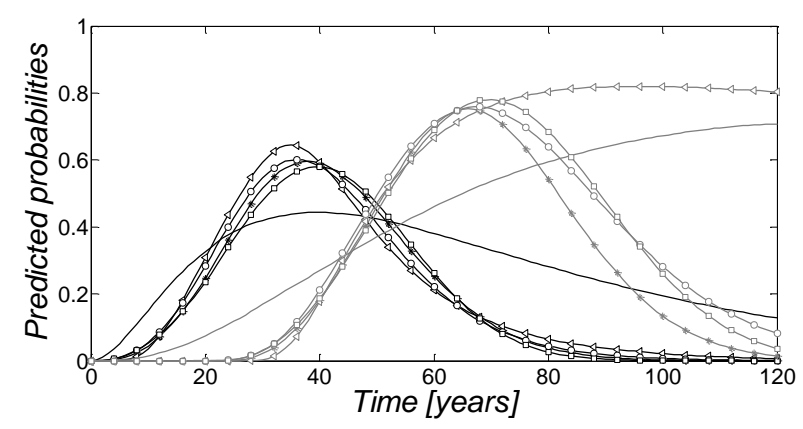

(b)

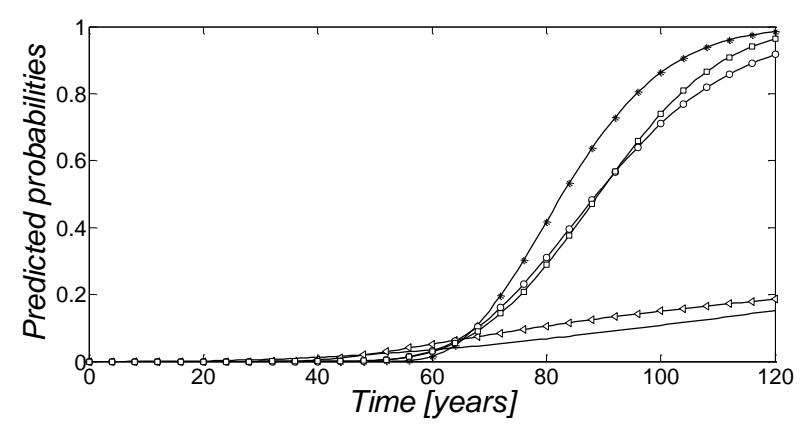

(c)

Figure 7. Probabilistic densities of all degradation condition levels over time: (a) Level A (black) and B (grey); (b) Level C (black) and D (grey); (c) Level E. 


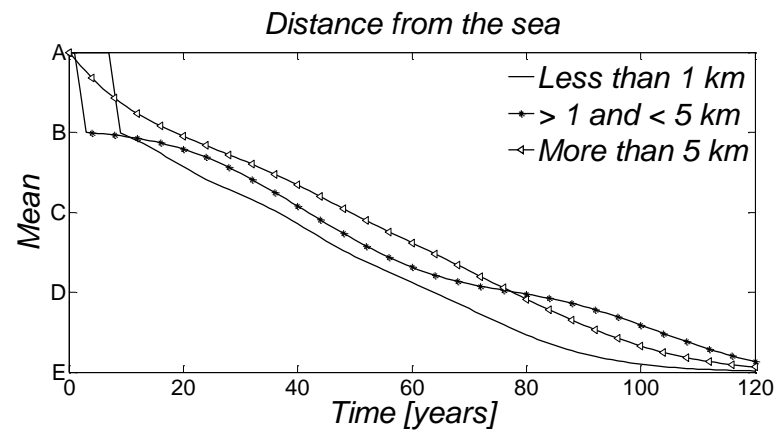

(a)

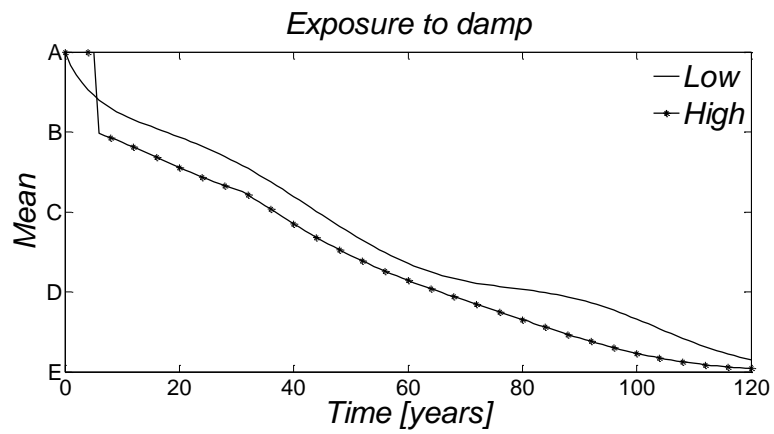

(b)

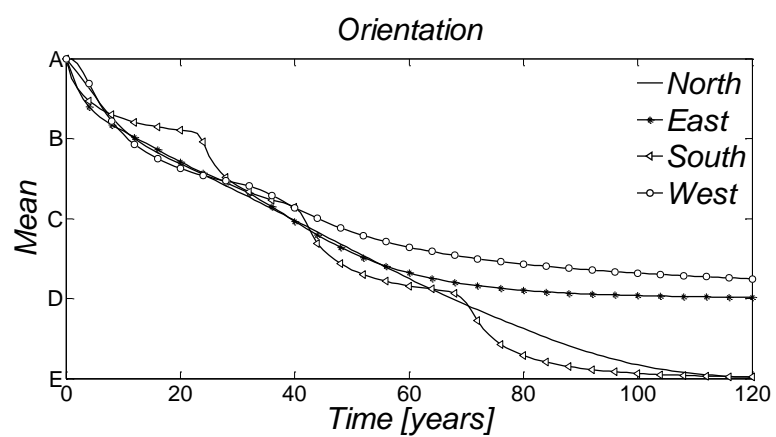

(c)

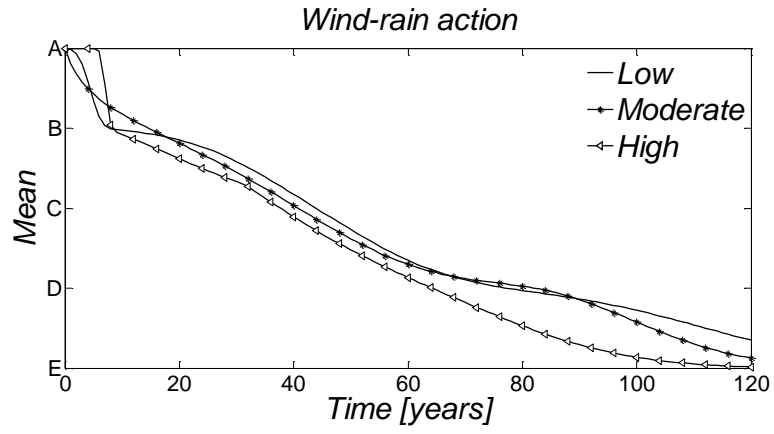

(d)

Figure 8. Predicted future condition profile over time for all variables. 

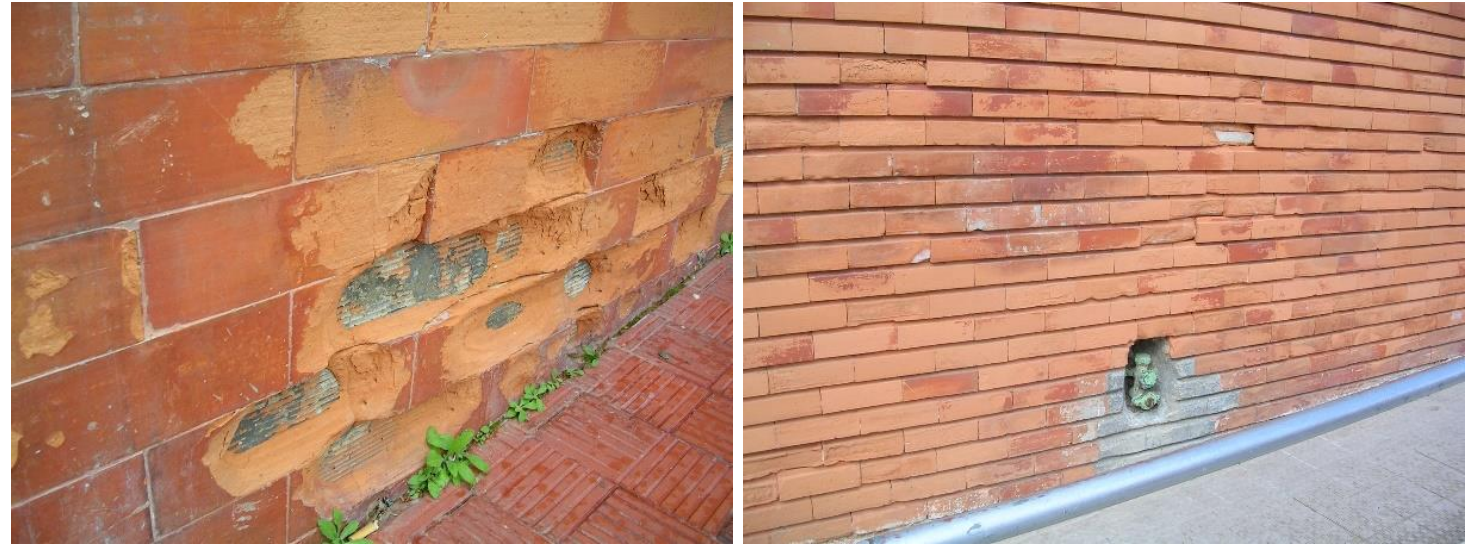

Figure 9. Illustrative example of the pathological situation of a case study located less than $5 \mathrm{~km}$ from the sea. 

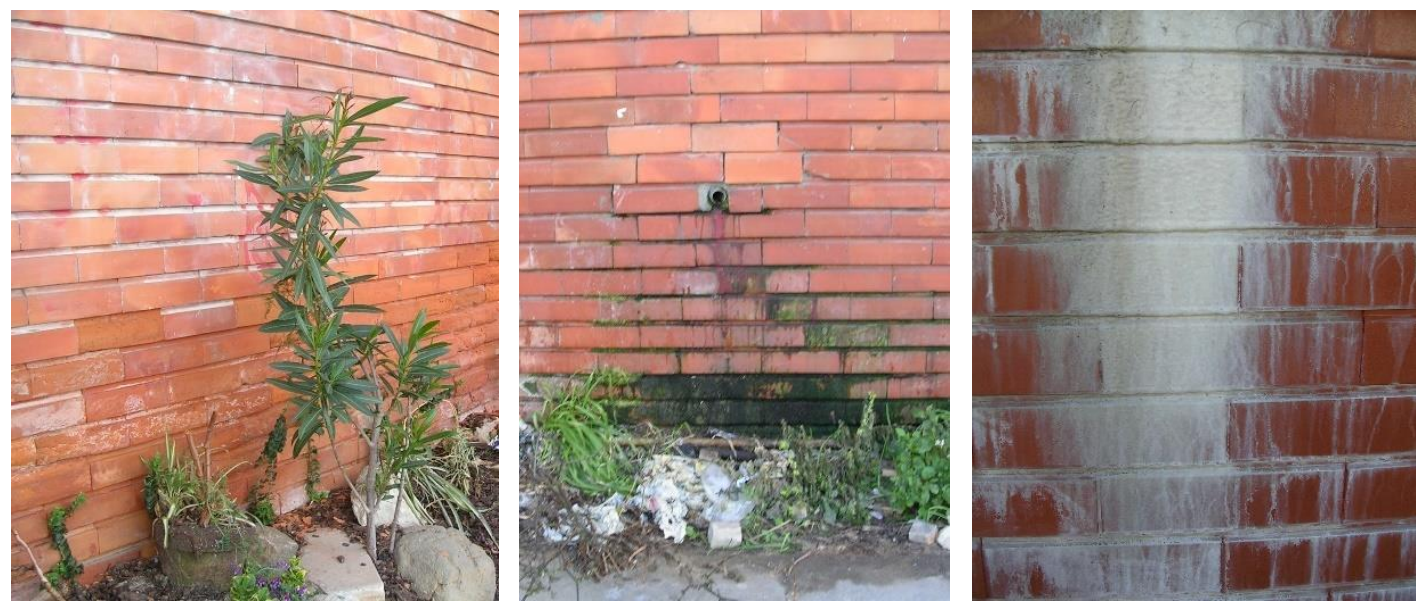

Figure 10. Most common defects in ceramic claddings due to the presence of damp. 

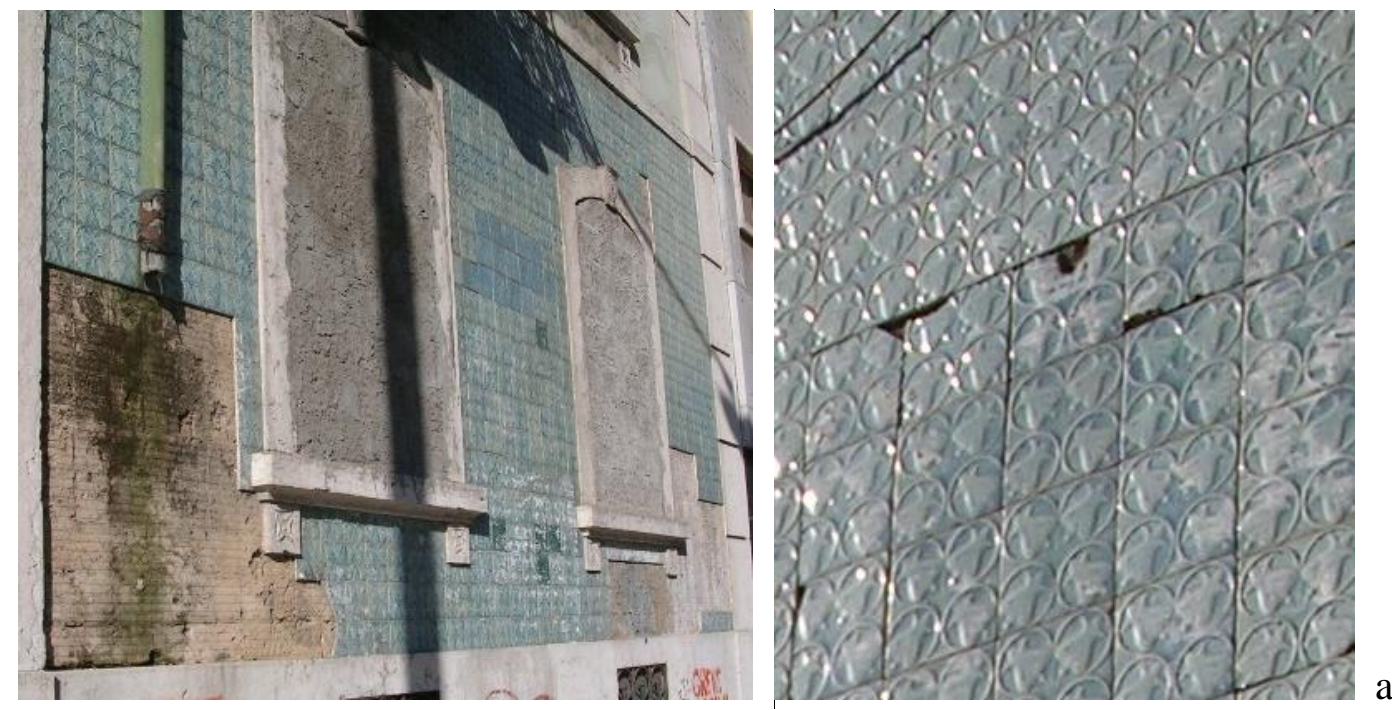

a)
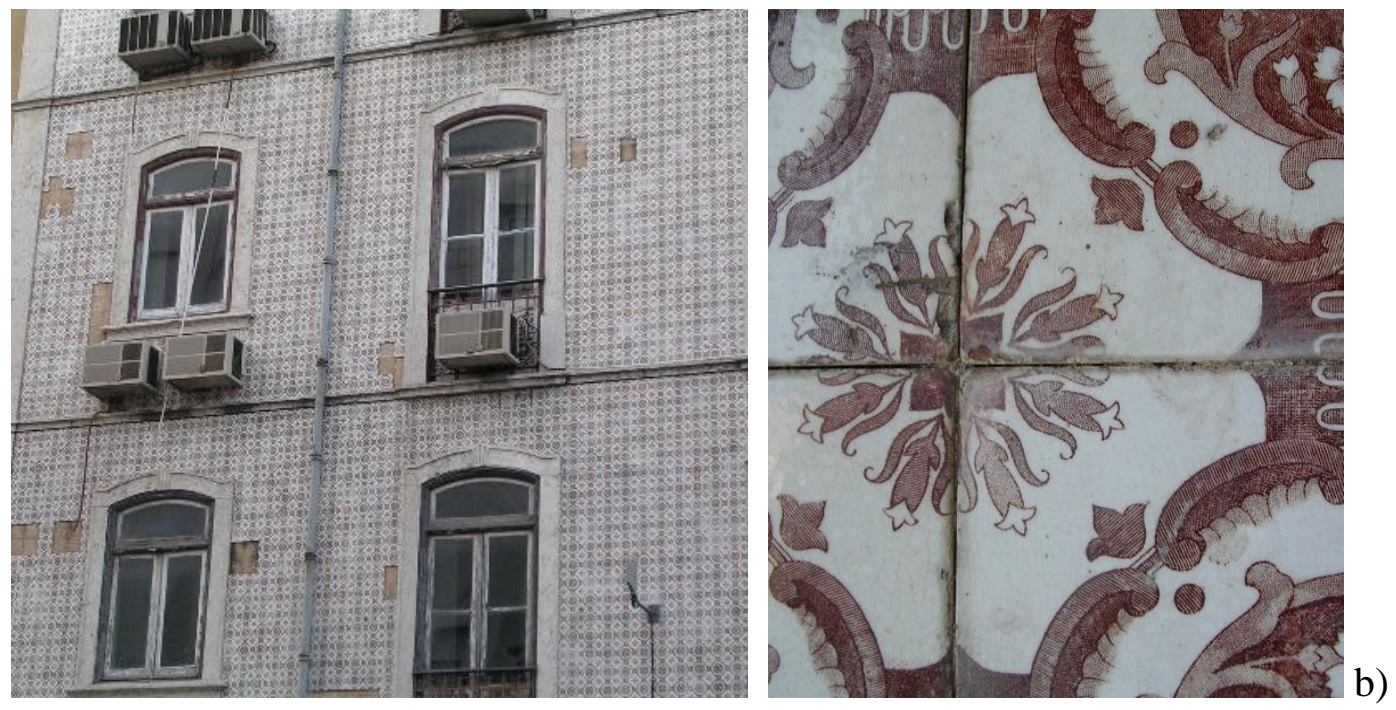

Figure 11. Illustrative example of the influence of the exposure to the wind-rain action in the degradation condition of ceramic claddings. 
Table 1. Degradation conditions for ceramic claddings (data sourced from Bordalo et al., 2011, and Galbusera et al., 2015).

\begin{tabular}{|c|c|c|c|c|c|}
\hline $\begin{array}{l}\text { Degradation } \\
\text { Levels }\end{array}$ & Groups of defects & Description & $k_{a, n}$ & $\begin{array}{l}\text { \% area of clad- } \\
\text { ding affected }\end{array}$ & $\begin{array}{l}\text { Severity of deg- } \\
\text { radation }(\%)\end{array}$ \\
\hline $\begin{array}{c}\text { Level A } \\
\left(k_{n}=0\right)\end{array}$ & $\begin{array}{l}\text { No visible degrada- } \\
\text { tion }\end{array}$ & - & - & 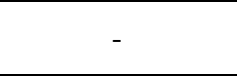 & $S_{w} \leq 1$ \\
\hline \multirow{8}{*}{$\begin{array}{l}\text { Level B } \\
\left(k_{n}=1\right)\end{array}$} & \multirow{6}{*}{$\begin{array}{l}\text { Visual or surface } \\
\text { degradation }\end{array}$} & - Surface dirt & 0.25 & \multirow{6}{*}{$\leq 10$} & \multirow{8}{*}{$1<S_{w} \leq 6$} \\
\hline & & - Small surface craters & 0.60 & & \\
\hline & & - Wear or scratches & 0.60 & & \\
\hline & & - Crushing or scaling of the borders & 0.60 & & \\
\hline & & - Change of shine and/or colour & 0.60 & & \\
\hline & & - Damp stains & 0.60 & & \\
\hline & Cracking & $\begin{array}{c}\text { - Cracked glazing } \\
\text { - Markedly orientated cracking }(<0.2 \\
\mathrm{mm})^{(1)} \text { without leakage }^{(*)}\end{array}$ & $\begin{array}{l}0.25 \\
1.00\end{array}$ & $\begin{array}{l}\text { Independent of } \\
\text { the affected area }\end{array}$ & \\
\hline & Joint deterioration & - Staining or change in colour & 0.25 & $\begin{array}{l}\text { Independent of } \\
\text { the affected area }\end{array}$ & \\
\hline \multirow{13}{*}{$\begin{array}{l}\text { Level C } \\
\left(k_{n}=2\right)\end{array}$} & \multirow{7}{*}{$\begin{array}{l}\text { Visual or surface } \\
\text { degradation }\end{array}$} & - Small surface craters & 0.60 & \multirow{7}{*}{$\begin{array}{c}>10 \text { and } \leq 50 \\
\leq 30\end{array}$} & \multirow{13}{*}{$6<S_{w} \leq 20$} \\
\hline & & - Wear or scratches & 0.60 & & \\
\hline & & - Crushing or scaling of the borders & 0.60 & & \\
\hline & & - Change of shine and/or colour & 0.60 & & \\
\hline & & - Damp stains & 0.60 & & \\
\hline & & - Biological growth & 1.00 & & \\
\hline & & - Efflorescence & 1.00 & & \\
\hline & & - Cracking with no predominant direction & 1.00 & & \\
\hline & Cracking & $\begin{array}{c}\text { - Markedly orientated cracking }(>0.2 \\
\text { mm })^{(2)} \text { without leakage }^{(*)}\end{array}$ & 1.00 & $\leq 30$ & \\
\hline & & - Without loss of filling material & 1.00 & & \\
\hline & Joint deterioration & - With loss of filling material & 1.50 & $\begin{array}{l}\leq 30 \\
\leq 10\end{array}$ & \\
\hline & & - Loss of adherence & 1.50 & $\leq 20$ & \\
\hline & Detachment & - Swelling & 1.50 & $\leq 20$ & \\
\hline \multirow{14}{*}{$\begin{array}{l}\text { Level D } \\
\left(k_{n}=3\right)\end{array}$} & & - Small surface craters & 0.60 & & \multirow{14}{*}{$20<S_{w} \leq 50$} \\
\hline & & - Wear or scratches & 0.60 & & \\
\hline & & - Crushing or scaling of the borders & 0.60 & & \\
\hline & Visual or surface & - Change of shine and/or colour & 0.60 & $>50$ & \\
\hline & degradation & - Damp stains & 0.60 & $>30$ & \\
\hline & & - Biological growth & 1.00 & & \\
\hline & & - Efflorescence & 1.00 & & \\
\hline & & - Cracking with no predominant direction & 1.00 & & \\
\hline & Cracking & $\begin{array}{l}\text { - Markedly orientated cracking }(>1 \mathrm{~mm})^{(3)} \\
\text { without leakage }^{(*)}\end{array}$ & 1.00 & $>30$ and $\leq 50$ & \\
\hline & & - Without loss of filling material & 1.00 & & \\
\hline & Joint deterioration & - With loss of filling material & 1.50 & $\begin{array}{l}>30 \text { and } \leq 50 \\
>10 \text { and } \leq 30\end{array}$ & \\
\hline & & - Loss of adherence & 1.50 & $>20$ & \\
\hline & Detachment & - Swelling & 1.50 & $>20$ & \\
\hline & & - Localized detachment & 2.00 & $\leq 10$ & \\
\hline \multirow{5}{*}{$\begin{array}{l}\text { Level E } \\
\left(k_{n}=4\right)\end{array}$} & & - Cracking with no predominant direction & 1.00 & & \multirow{5}{*}{$S_{w}>50$} \\
\hline & Cracking & - Markedly orientated cracking $(>5 \mathrm{~mm})^{(4)}$ & 1.00 & $>50$ & \\
\hline & & - Without loss of filling material & 1.00 & $>50$ & \\
\hline & Joint deterioration & - With loss of filling material & 1.50 & $>30$ & \\
\hline & Detachment & - Generalized detachment & 2.00 & $>10$ & \\
\hline \multicolumn{6}{|c|}{$\begin{array}{l}\text { (*) With leakage - the degradation level is increased by one. } \\
\text { (1) Cracking, detectable at a distance greater than } 5 \mathrm{~m} \text { only if binoculars are used. } \\
\text { (2) Tenuous cracking line, easily detectable at a distance greater than } 5 \mathrm{~m} \text {, using binoculars. } \\
\text { (3) Well defined cracking visible from a distance of more than } 5 \mathrm{~m} \text {, without using binoculars. } \\
\text { (4) Cracking characterized by a thick line in which a clear separation of the borders can be seen, from a distance of more than } 5 \mathrm{~m} \text {, with } \\
\text { the aid of binoculars. }\end{array}$} \\
\hline
\end{tabular}


Table 2. Optimal parameters obtained in all probability distribution analysed.

\begin{tabular}{|c|c|c|c|c|c|c|}
\hline \multicolumn{2}{|c|}{ Parameters } & Exponential & Weibull & Lognormal & Gumbel & Normal \\
\hline \multirow{4}{*}{$\sum^{\stackrel{\Xi}{\Sigma}}$} & $T_{1}$ & 6.69 & 6.84 & 6.39 & 6.70 & 7.70 \\
\hline & $T_{2}$ & 24.88 & 23.50 & 24.51 & 22.72 & 22.70 \\
\hline & $T_{3}$ & 39.93 & 22.60 & 23.95 & 22.72 & 22.13 \\
\hline & $T_{4}$ & 317.60 & 31.46 & $3.34 \times 10^{4}$ & 38.90 & 37.12 \\
\hline \multirow{4}{*}{ 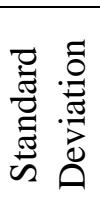 } & $T_{1}$ & 6.69 & 6.24 & 6.59 & 5.57 & 5.80 \\
\hline & $T_{2}$ & 24.88 & 12.37 & 17.73 & 13.79 & 12.08 \\
\hline & $T_{3}$ & 39.93 & 1.42 & 0.54 & 2.55 & 0.32 \\
\hline & $T_{4}$ & 317.60 & 1.93 & $1.52 \times 10^{6}$ & 13.07 & 9.53 \\
\hline \multicolumn{2}{|c|}{ Likelihood } & 180.2441 & 160.1749 & 162.3466 & 160.8896 & 160.6454 \\
\hline
\end{tabular}


Table 3. Number of observed and predicted claddings in each condition level for each probability distribution and mean error obtained for each probability distribution.

\begin{tabular}{|c|c|c|c|c|c|c|}
\hline & Level A & Level B & Level C & Level D & Level E \\
\hline \multicolumn{2}{|c|}{ Number of observed claddings } & 15 & 70 & 64 & 43 & 3 \\
\hline \multirow{5}{*}{ 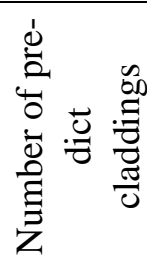 } & Exponential & 16.40 & 64.88 & 67.30 & 43.86 & 2.56 \\
\hline & Weibull & 16.69 & 67.12 & 66.76 & 42.12 & 2.31 \\
\hline & Lognormal & 15.65 & 66.67 & 68.32 & 41.59 & 2.77 \\
\hline & Gumbel & 16.24 & 64.14 & 66.95 & 45.31 & 2.36 \\
\hline & Normal & 18.64 & 65.63 & 65.97 & 42.64 & 2.13 \\
\hline \multirow{5}{*}{ 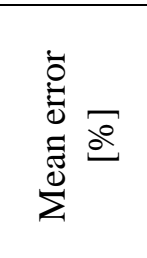 } & Exponential & 9.3 & 7.3 & 5.2 & 2.0 & 14.5 \\
\hline & Weibull & 11.2 & 4.1 & 4.3 & 2.0 & 23.0 \\
\hline & Lognormal & 4.4 & 4.8 & 6.7 & 3.3 & 7.7 \\
\hline & Gumbel & 8.3 & 8.4 & 4.6 & 5.4 & 21.3 \\
\hline & Normal & 24.3 & 6.2 & 3.1 & 0.8 & 29.1 \\
\hline
\end{tabular}


Table 4. Comparison of the optimal parameters of the Markov chains and Petri nets models.

\begin{tabular}{|c|c|c|c|}
\hline \multicolumn{2}{|c|}{ Parameters } & Markov chains $^{1}$ & Petri net (exponential) \\
\hline \multirow{4}{*}{$\stackrel{\Xi}{\Sigma}^{\Xi}$} & $T_{1}$ & 6.58 & 6.69 \\
\hline & $T_{2}$ & 24.81 & 24.88 \\
\hline & $T_{3}$ & 39.68 & 39.93 \\
\hline & $T_{4}$ & 100.00 & 317.60 \\
\hline \multirow{4}{*}{ 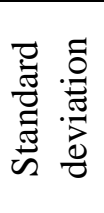 } & $T_{1}$ & 6.58 & 6.69 \\
\hline & $T_{2}$ & 24.81 & 24.88 \\
\hline & $T_{3}$ & 39.68 & 39.93 \\
\hline & $T_{4}$ & 100.00 & 317.60 \\
\hline \multicolumn{2}{|c|}{ Likelihood } & 183.8355 & 180.2441 \\
\hline
\end{tabular}


Table 5. ANOVA test results.

\begin{tabular}{ccc}
\hline $\begin{array}{c}\text { Time horizon } \\
\text { [years] }\end{array}$ & $\begin{array}{c}\text { Critical value } \\
\text { of the } \boldsymbol{F} \text {-ratio }\end{array}$ & $\boldsymbol{p}$-value \\
\hline 10 & 5784.4 & 0 \\
20 & 5983.3 & 0 \\
30 & 3040.1 & 0 \\
40 & 2743.7 & 0 \\
50 & 3440.8 & 0 \\
\hline
\end{tabular}


Table 6. Pairwise comparison.

\begin{tabular}{ccccccc}
\hline \multirow{2}{*}{ Pairwise } & \multicolumn{5}{c}{ Time horizon [years] } \\
\cline { 3 - 7 } & & $\mathbf{1 0}$ & $\mathbf{2 0}$ & $\mathbf{3 0}$ & $\mathbf{4 0}$ & $\mathbf{5 0}$ \\
\hline G & DL & 11.91 & 45.99 & 50.99 & 38.03 & 25.35 \\
G & DH & 118.79 & 79.18 & 51.42 & 48.43 & 42.96 \\
G & SI & 90.37 & 2.88 & 11.38 & 8.04 & 5.45 \\
G & SF & 53.71 & 53.01 & 62.77 & 75.65 & 82.88 \\
G & SC & 87.34 & 76.64 & 68.20 & 48.95 & 45.46 \\
G & OE & 33.98 & 30.36 & 20.56 & 21.35 & 16.47 \\
G & ON & 26.42 & 37.97 & 34.13 & 18.28 & 6.11 \\
G & OW & 51.68 & 59.23 & 3.35 & 22.79 & 48.50 \\
G & OS & 22.97 & 101.18 & 12.78 & 23.39 & 67.51 \\
G & WH & 99.90 & 60.07 & 35.40 & 38.84 & 37.56 \\
G & WM & 6.53 & 1.31 & 2.66 & 5.18 & 6.13 \\
G & WL & 80.33 & 18.34 & 39.59 & 33.58 & 24.90 \\
\hline DL & DH & 130.70 & 125.17 & 102.40 & 86.46 & 68.30 \\
\hline SI & SF & 144.08 & 55.89 & 51.39 & 67.61 & 77.43 \\
SI & SC & 3.02 & 73.75 & 79.58 & 56.98 & 50.90 \\
SF & SC & 141.05 & 129.64 & 130.97 & 124.59 & 128.34 \\
\hline OE & ON & 7.56 & 7.61 & 13.57 & 3.07 & 10.36 \\
OE & OW & 17.70 & 28.87 & 17.21 & 44.14 & 64.97 \\
OE & OS & 56.96 & 131.54 & 7.78 & 44.74 & 51.04 \\
ON & OW & 25.27 & 21.26 & 30.78 & 41.07 & 54.61 \\
ON & OS & 49.39 & 139.15 & 21.35 & 41.68 & 61.40 \\
OW & OS & 74.66 & 160.41 & 9.43 & 0.60 & 116.01 \\
\hline WH & WM & 93.37 & 61.38 & 32.74 & 33.66 & 31.43 \\
WH & WL & 19.58 & 78.41 & 74.99 & 72.42 & 62.46 \\
WM & WL & 73.80 & 17.04 & 42.25 & 38.76 & 31.03 \\
\hline
\end{tabular}

Caption: G - Complete sample; DL - Low exposure to damp; DH - High exposure to damp; SC - Close to the sea (less than $1 \mathrm{~km}$ ); SF - Far away from the sea (more than $5 \mathrm{~km}$ ); SI Intermediate position from the sea (between 1 and $5 \mathrm{~km}$ ); ON - Orientation-north; OE Orientation-east; OS - Orientation-south; OW - Orientation-west; WL - Low exposure to wind-rain action; WM - Moderate exposure to wind-rain action; and WH - High exposure to wind-rain action. 
Table 7. Probability of belonging to a condition as a function of the variables considered.

\begin{tabular}{|c|c|c|c|c|c|c|c|c|}
\hline Variables & Distribution & $\begin{array}{c}\text { Level A } \\
{[\%]}\end{array}$ & $\begin{array}{c}\text { Level B } \\
{[\%]}\end{array}$ & $\begin{array}{c}\text { Level C } \\
{[\%]}\end{array}$ & $\begin{array}{c}\text { Level D } \\
{[\%]}\end{array}$ & $\begin{array}{c}\text { Level E } \\
{[\%]}\end{array}$ & $\begin{array}{c}\text { Log-likeli- } \\
\text { hood }\end{array}$ & $\begin{array}{c}\text { Normalized } \\
\text { log-likelihood }\end{array}$ \\
\hline Complete sample & Weibull & 8.6 & 34.4 & 34.2 & 21.6 & 1.2 & 160.17 & 0.8214 \\
\hline \multicolumn{9}{|l|}{ Distance from the sea } \\
\hline Less than $1 \mathrm{~km}$ & Gumbel & 7.8 & 20.5 & 37.2 & 31.1 & 3.4 & 52.43 & 0.6809 \\
\hline Between 1 and $5 \mathrm{~km}$ & Normal & 3.3 & 33.9 & 34.1 & 28.7 & 0.0 & 42.96 & 0.6929 \\
\hline More than $5 \mathrm{~km}$ & Weibull & 13.9 & 56.2 & 26.9 & 3.0 & 0.0 & 45.88 & 0.8193 \\
\hline \multicolumn{9}{|l|}{ Exposure to damp } \\
\hline Low & Weibull & 8.8 & 45.4 & 29.7 & 16.1 & 0.0 & 87.87 & 0.7916 \\
\hline High & Normal & 7.1 & 22.3 & 37.2 & 30.9 & 2.5 & 57.73 & 0.6872 \\
\hline \multicolumn{9}{|l|}{ Orientation } \\
\hline North & Normal & 10.3 & 21.8 & 44.2 & 21.9 & 1.9 & 44.85 & 0.7733 \\
\hline East & Lognormal & 8.3 & 33.5 & 29.6 & 28.6 & 0.0 & 31.54 & 0.7885 \\
\hline South & Weibull & 8.6 & 38.3 & 21.9 & 27.1 & 4.1 & 24.63 & 0.6006 \\
\hline West & Lognormal & 8.8 & 41.3 & 36.2 & 13.7 & 0.0 & 37.09 & 0.8626 \\
\hline \multicolumn{9}{|l|}{ Wind-rain action } \\
\hline Low & Normal & 2.3 & 41.6 & 37.1 & 18.9 & 0.2 & 33.64 & 0.7476 \\
\hline Moderate & Weibull & 10.9 & 40.0 & 32.2 & 16.9 & 0.0 & 77.32 & 0.7972 \\
\hline High & Normal & 7.5 & 18.8 & 33.9 & 34.9 & 4.9 & 40.14 & 0.7573 \\
\hline
\end{tabular}

